Dos Santos Alves, W., Scopel, I. y Perini Martins, A. (2017): “Análise da fragilidade ambiental da bacia do Ribeirão das Abóboras, em Rio Verde, Sudoeste de Goiás”, GeoFocus (Artículos), no 19, p. 81-108. ISSN: 1578-5157 http://dx.doi.org/10.21138/GF.556

\title{
ANÁLISE DA FRAGILIDADE AMBIENTAL DA BACIA DO RIBEIRÃO DAS ABÓBORAS, EM RIO VERDE, SUDOESTE DE GOIÁS
}

\author{
WELLMO DOS SANTOS ALVES ${ }^{1}$, IRACI SCOPEL ${ }^{2}$, ALÉCIO PERINI MARTINS ${ }^{2}$ \\ ${ }^{1}$ Instituto Federal de Educação, Ciência e Tecnologia Goiano - Campus Rio Verde. Rod. Sul \\ Goiana, S/N, km 01, Zona Rural, CEP 75901970. Rio Verde (GO). \\ wellmo.alves@ifgoiano.edu.br \\ ${ }^{2}$ Universidade Federal de Goiás/Regional Jataí Unidade Riachuelo. Rua Riachuelo, 1530 - B. \\ Samuel Graham, CEP 75800-000. Jataí (GO). \\ iraciscopel@gmail.com, alecioperini@yahoo.com.br
}

\section{RESUMO}

Objetivou-se avaliar a fragilidade ambiental da bacia do Ribeirão das Abóboras $\left(199,1 \mathrm{~km}^{2}\right)$, localizada no município de Rio Verde, Sudoeste de Goiás. Utilizou-se o método proposto por Ross (1994), baseado em classes de declividade, solos, erosividade, uso da terra e cobertura vegetal. A área de estudo apresenta: fragilidade ambiental potencial com predominância da classe baixa $(72,73 \%)$, seguida pela classe muito baixa $(23,40 \%)$ e classe alta $(3,87 \%)$; médio risco de erosividade $\left(643,04 \mathrm{tn}^{-h^{-1}} \cdot \mathrm{ano}^{-1}\right)$; e fragilidade ambiental emergente com maior extensão da classe média $(78,96 \%)$, seguida pela classe baixa $(20,60 \%)$ e classe alta $(0,35 \%)$. Estes resultados inferem que a bacia apresenta condições físicas e climáticas, na sua maior parte, favoráveis à sua conservação, mas o manejo dos solos inadequado, principalmente nas áreas com aspectos favoráveis à erosão, está causando prejuízos ambientais e, consequentemente, econômicos.

Palavras-chave: Bacia hidrográfica, geotecnologias, gestão ambiental.

\section{ANALYSIS OF THE ENVIRONMENTAL FRAGILITY OF THE RIVER BASIN OF RIBEIRÃO DAS ABÓBORAS, IN RIO VERDE, SOUTH-WEST OF GOIÁS STATE}

\section{ABSTRACT}

The objective of this paper was evaluating the environmental fragility of the river basin of Ribeirão das Abóboras (199.1 km²), located in the municipality of Rio Verde, South-west of Goiás state. The method proposed by Ross (1994) has been used, based on declivity classes, soils, erosivity, land use and vegetation coverage. The study area presents: a potential environmental fragility with predominance of a low class $(72.73 \%)$, followed by a very low class $(23.40 \%)$ and a high class $(3.87 \%)$; average risk of erosivity (643.04 tn.ha ${ }^{-1}$.year $\left.{ }^{-1}\right)$; and emerging environmental fragility with a higher extension of the average class $(78.96 \%)$, followed by the low class $(20.60 \%)$ and the high class $(0.35 \%)$. These results interfere that the basin presents physical and climatic conditions, in its majority, favorable to its conservation 
Dos Santos Alves, W., Scopel, I. y Perini Martins, A. (2017): “Análise da fragilidade ambiental da bacia do Ribeirão das Abóboras, em Rio Verde, Sudoeste de Goiás”, GeoFocus (Artículos), no 19, p. 81-108. ISSN: 1578-5157 http://dx.doi.org/10.21138/GF.556

however the, inadequate soil management, mainly in areas with favorable aspects to erosion, it's causing environmental and, consequently, economic losses.

Keywords: River basin, geotechnologies, environmental management.

\section{Introdução}

A influência antrópica no ambiente, inclusive em bacias hidrográficas, tem sido motivo frequente de preocupação na sociedade (Gonçalves et al., 2011). Em função disto, conforme Donha, Souza e Sugamosto (2006), torna-se cada vez mais urgente o planejamento físico territorial, não só com enfoque socioeconômico, deve visar também o meio ambiente, levandose em consideração não apenas as potencialidades, mas principalmente a fragilidade das áreas com intervenções antrópicas.

Conforme Spörl e Ross (2004), os sistemas ambientais, face às intervenções humanas, apresentam maior ou menor fragilidade em função de suas características "genéticas"; sendo que qualquer alteração nos diferentes componentes da natureza, como relevo, solo, vegetação, clima e recursos hídricos, acarreta o comprometimento da funcionalidade do sistema, quebrando o seu estado de equilíbrio dinâmico.

Donha, Souza e Sugamosto (2006) ressaltam que para se determinar as potencialidades dos recursos naturais, torna-se necessário um estudo dos componentes que dão suporte à vida, sendo eles: solos, relevo, geologia, água, clima e vegetação. Estes autores ressaltam ainda que na análise da fragilidade, esses componentes devem ser avaliados de maneira integrada, considerando-se sempre as intervenções antrópicas modificadoras dos ambientes naturais.

Os dados obtidos utilizando-se com ferramentas de sensoriamento remoto e geoprocessamento constituem-se numa das principais fontes geradoras de informações para o planejamento ambiental, sendo que diversas pesquisas se apoiam nesses dados para análises da fragilidade dos ambientes naturais e antropizados.

A fragilidade desses ambientes pode ser mais facilmente analisada aplicando, em ambiente SIG, a metodologia proposta por Ross (1994) em "Análise Empírica da Fragilidade dos Ambientes Naturais e Antropizados", com base no princípio de que a natureza apresenta funcionalidade intrínseca entre seus componentes físicos e bióticos.

Para o entendimento da fragilidade ambiental é imprescindível o conhecimento sobre a fragilidade potencial e fragilidade emergente, sendo a primeira a vulnerabilidade natural de um ambiente em função de seus atributos físicos como a declividade, o tipo de solo e a precipitação; e a segunda refere-se aos graus de proteção dos diferentes tipos de uso e cobertura da terra em relação ao meio (Ross, 1994; Kawakubo et al., 2005; Donha; Sousa; Sugamosto, 2006; Gonçalves et al., 2011; Martins; Rodrigues, 2012).

A bacia do Ribeirão das Abóboras é a principal fonte de água da população urbana de Rio Verde, município mais importante na microrregião Sudoeste de Goiás, onde, conforme IBGE (2017), reside a quarta maior população goiana, estimada em 212.237 habitantes. Essa bacia hidrográfica também é a fonte de água do processo produtivo da BRF unidade de Rio Verde (GO) (antiga Perdigão S. A.), uma das maiores companhias de alimentos do mundo, que fornece 
Dos Santos Alves, W., Scopel, I. y Perini Martins, A. (2017): “Análise da fragilidade ambiental da bacia do Ribeirão das Abóboras, em Rio Verde, Sudoeste de Goiás”, GeoFocus (Artículos), no 19, p. 81-108. ISSN: 1578-5157 http://dx.doi.org/10.21138/GF.556

produtos para a alimentação local e exporta para todo o Brasil e diversos países, além de ser fonte de água para irrigação, dessedentação de animais e outros usos.

O município de Rio Verde (GO) é destaque na produção agropecuária, principalmente na produção de grãos, com destaque na produção de soja, milho, aves e suínos. As principais granjas, que fornecem matéria prima para o processo produtivo da BRF, e inclusive esta, uma das maiores companhias de alimento do mundo, estão instaladas na bacia do Ribeirão das Abóboras. Esse sucesso na economia é em decorrência do nível elevado de tecnologias usadas, uso intensivo dos solos, relevos favoráveis, proximidade dos grandes centros, vias de acesso, políticas públicas dentre outros, muitas vezes sem visar a sustentabilidade do agroecossistema. Assim, a bacia do Ribeirão das Abóboras é de importância global, sendo fundamental a elaboração de bases de dados geográficos para subsidiar a sua gestão ambiental.

Diante da importância do estudo da fragilidade ambiental para a gestão dos recursos naturais, e tendo como base a metodologia descrita por Ross (1994), esta pesquisa tem como objetivo estudar de forma integrada os componentes ambientais declividade, solos, uso da terra, cobertura vegetal e erosividade da bacia do Ribeirão das Abóboras no município de Rio Verde (GO), no intuito de indicar as áreas potenciais à erosão, as de preservação e tipo de uso, através da obtenção de dados de Sensoriamento Remoto e de técnicas de Geoprocessamento, e subsidiar o planejamento ambiental dessa bacia hidrográfica.

\section{Material e métodos}

As bases de dados usadas nesta pesquisa foram disponibilizadas pelo United States Geological Survey (USGS), Sistema Estadual de Geoinformação de Goiás (SIEG) e Banco de Dados Meteorológico para Ensino e Pesquisa (BDMEP).

A fase de geoprocessamento foi realizada no Software ArcGIS $10.1^{\circledR}$, licenciado para o laboratório de Geoinformação da Universidade Federal de Goiás (UFG)/Regional Jataí.

\section{1 Área de estudo}

A bacia do Ribeirão das Abóboras está localizada no município de Rio Verde no Estado de Goiás, Brasil (Figura 1), sendo que este Ribeirão nasce no local com coordenadas geográficas de $50^{\circ} 58^{\prime} 8,239^{\prime \prime} \mathrm{W}$ e $17^{\circ} 45^{\prime} 4,927^{\prime \prime} \mathrm{S}$, e sua foz está localizada na altitude de $640 \mathrm{~m}$, nas coordenadas de $50^{\circ} 55^{\prime} 0,677^{\prime \prime} \mathrm{W}$ e $17^{\circ} 54^{\prime} 43,223^{\prime \prime} \mathrm{S}$, na margem direita do Rio São Tomás. 
Dos Santos Alves, W., Scopel, I. y Perini Martins, A. (2017): “Análise da fragilidade ambiental da bacia do Ribeirão das Abóboras, em Rio Verde, Sudoeste de Goiás”, GeoFocus (Artículos), no 19, p. 81-108. ISSN: 1578-5157 http://dx.doi.org/10.21138/GF.556

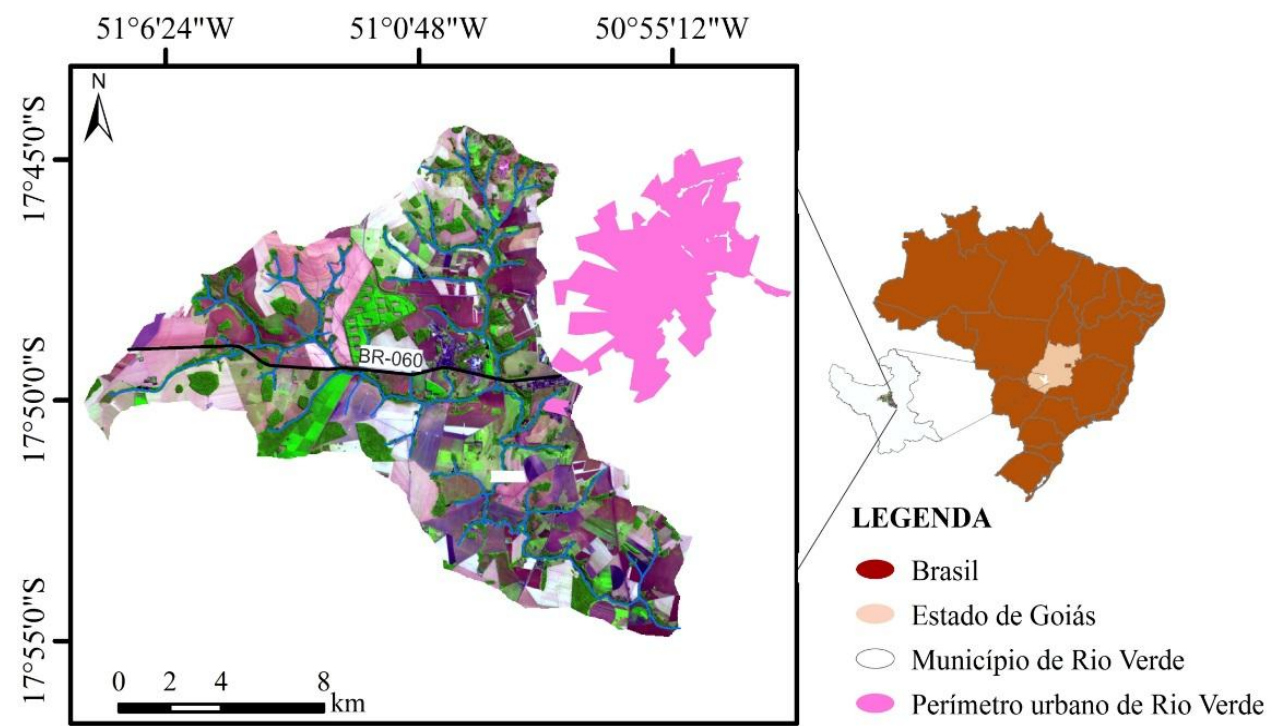

Figura 1. Localização da bacia do Ribeirão das Abóboras no município de Rio Verde, Estado de Goiás, Brasil.

Fonte: Elaborado pelos autores a partir de bases geográficas cedidas pelo SIEG (2016).

Para melhor caracterizar e compreender a área de estudo, foram elaborados mapas da hidrografia, geologia, geomorfologia e altimetria.

A bacia do Ribeirão das Abóboras apresenta como seus principais afluentes: Córrego Curicaca, Córrego Retiro, Córrego Buriti, Córrego Sucuri, Córrego Aterradinho-de-cima, Córrego Mutum, Córrego Olaria, Córrego do Queixada, Córrego Mata-burro e Córrego Marimbondo, sendo este último o principal afluente do Ribeirão das Abóboras (Figura 2). 
Dos Santos Alves, W., Scopel, I. y Perini Martins, A. (2017): “Análise da fragilidade ambiental da bacia do Ribeirão das Abóboras, em Rio Verde, Sudoeste de Goiás”, GeoFocus (Artículos), no 19, p. 81-108. ISSN: 1578-5157 http://dx.doi.org/10.21138/GF.556

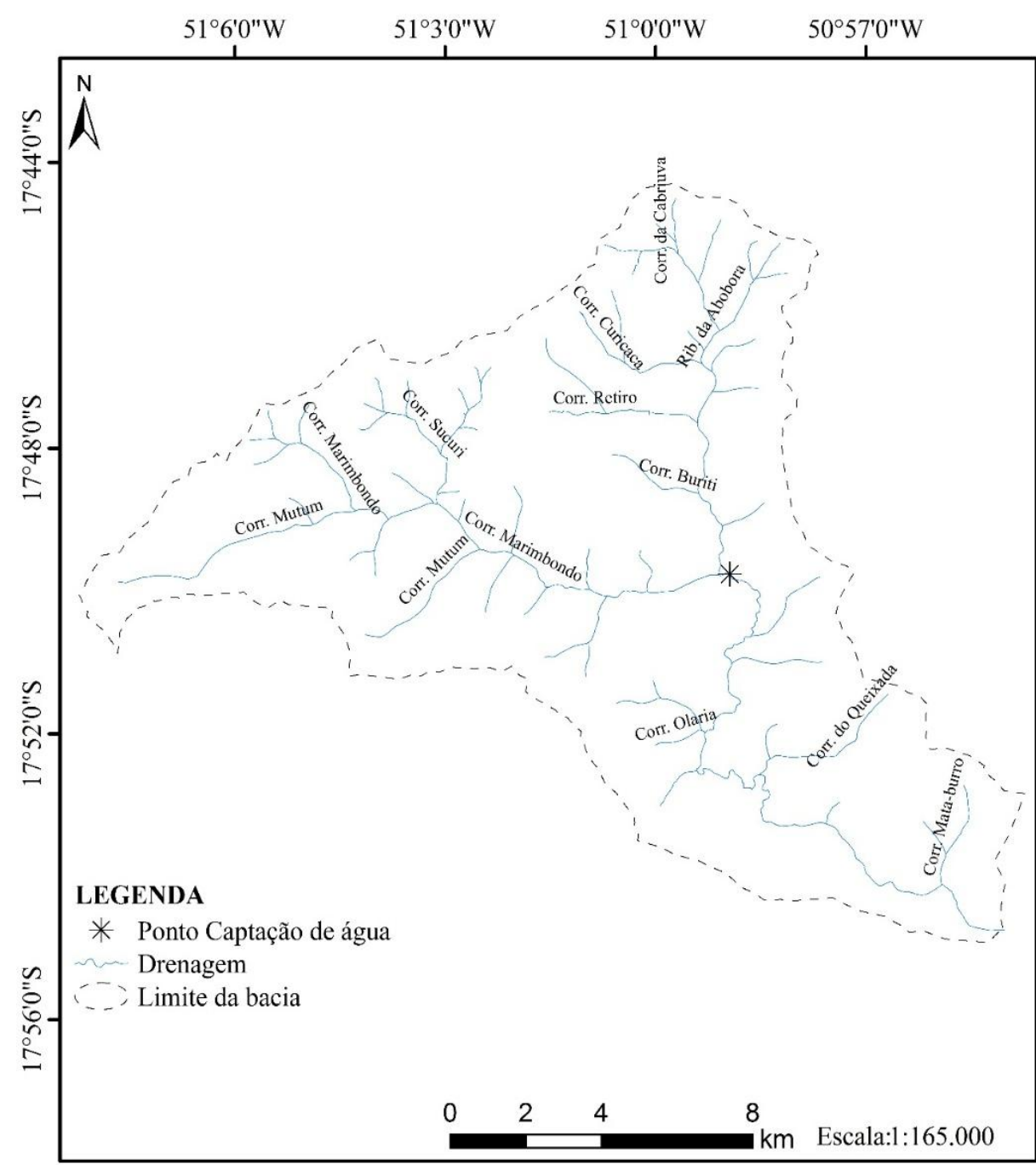

Figura 2. Mapa hidrográfico do Ribeirão das Abóboras, localizado no município de Rio Verde (GO).

Fonte: Elaborado pelos autores a partir da base hidrográfica de Goiás cedida pelo SIEG (2016).

Em função de suas características mineralógicas, textuais e estruturais, os corpos rochosos respondem diferentemente à ação dos processos exógenos, influenciando nas formas de relevo e tipos de solo (BOTELHO, 1999). A bacia do Ribeirão das Abóboras está inserida no Planalto Setentrional da Bacia Sedimentar do Paraná (SIEG, 2016).

Conforme o Mapa Geológico de Goiás e Distrito Federal disponibilizado pelo SIEG (2016), as rochas que embasam a bacia do Ribeirão são de idades que oscilam entre o Cretáceo e o Neogeno e os produtos litológicos são (Tabela 1):

Formação Vale do Rio do Peixe, com maior extensão;

Rochas sedimentares: Grupo Bauru -

-

indiferenciadas, segunda maior área; e

Unidade coberturas detríticas 
Dos Santos Alves, W., Scopel, I. y Perini Martins, A. (2017): “Análise da fragilidade ambiental da bacia do Ribeirão das Abóboras, em Rio Verde, Sudoeste de Goiás”, GeoFocus (Artículos), no 19, p. 81-108. ISSN: 1578-5157 http://dx.doi.org/10.21138/GF.556

- Ígneas vulcânicas: Grupo São Bento - Formação Serra Geral, em menor percentual.

Os dois grupos geológicos e a unidade coberturas detríticas indiferenciadas presentes na bacia do Ribeirão das Abóboras são espacializados na Figura 3.

Tabela 1. Classes de geologia da bacia do Ribeirão das Abóboras, localizada no município de Rio Verde (GO).

\begin{tabular}{|c|c|c|c|}
\hline Classe & Litotipo & $\mathbf{k m}^{2}$ & $\%$ \\
\hline $\begin{array}{l}\text { Grupo Bauru - Formação Vale do Rio do } \\
\text { Peixe. }\end{array}$ & Arenito, argilito arenoso. & 124,91 & 62,74 \\
\hline Coberturas detríticas indiferenciadas. & $\begin{array}{l}\text { Depósitos de areia, } \\
\text { depósitos de cascalho, } \\
\text { depósitos de argila. }\end{array}$ & 39,60 & 19,89 \\
\hline Grupo São Bento - Formação Serra Geral. & Basalto, basalto-andesito. & 34,59 & 17,37 \\
\hline Total & & 199,1 & 100 \\
\hline
\end{tabular}

Fonte: Elaborado pelos autores a partir da base geológica de Goiás e Distrito Federal cedida pelo SIEG (2016).

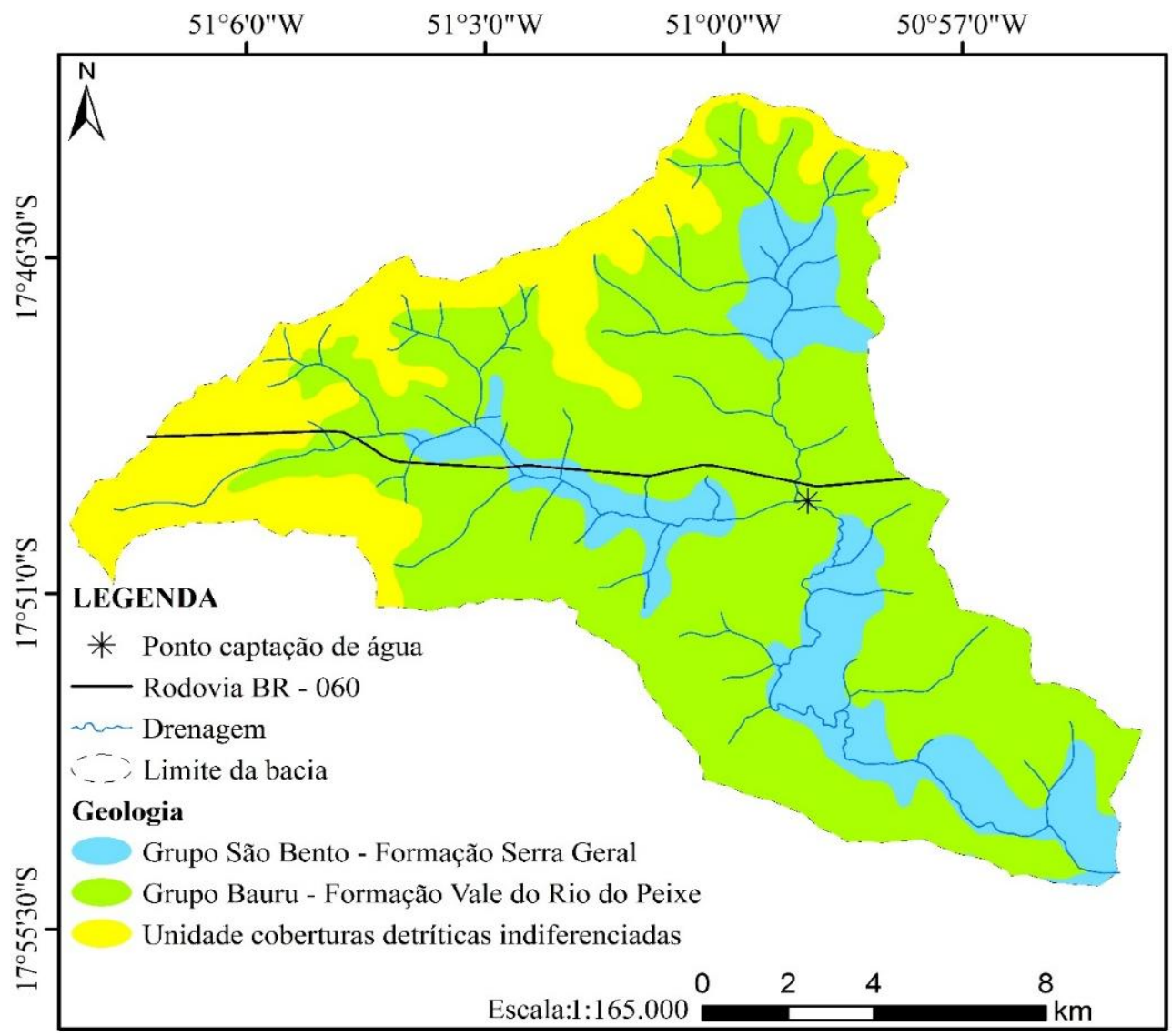

Figura 3. Mapa geológico da bacia do Ribeirão das Abóboras, localizada no município de Rio Verde (GO).

Fonte: Elaborado pelos autores a partir da base geológica de Goiás e Distrito Federal cedida pelo SIEG (2016). 
Dos Santos Alves, W., Scopel, I. y Perini Martins, A. (2017): “Análise da fragilidade ambiental da bacia do Ribeirão das Abóboras, em Rio Verde, Sudoeste de Goiás”, GeoFocus (Artículos), no 19, p. 81-108. ISSN: 1578-5157 http://dx.doi.org/10.21138/GF.556

Quanto à geomorfologia, conforme Latrubesse e Carvalho (2006), podendo ser observado na Tabela 2, com ilustração na Figura 4, Figura 5 e Figura 6, apresenta:

- Superfície Regional de Aplainamento IIIB com cotas entre 650 e 750 m, com dissecação média e associada a Relevos Tabulares, maior representatividade (SRAIIIB-RT); e

- Superfície Regional de Aplainamento IIB com cotas entre 800 e 1000 m, com dissecação média e associada a Relevos Tabulares, com menor área (SRAIIB-RT).

Tabela 2. Classes de geomorfologia da bacia do Ribeirão das Abóboras, localizada no município de Rio Verde (GO).

\begin{tabular}{ccc}
\hline Classe & $\mathbf{k m}^{\mathbf{2}}$ & $\mathbf{\%}$ \\
\hline SRAIIIB-RT & 178,43 & 89,62 \\
SRAIIB-RT & 20,66 & 10,38 \\
\hline Total & 199,1 & 100 \\
\hline
\end{tabular}

SRAIIIB-RT: Superfície Regional de Aplainamento IIIB com cotas entre 650 e 750 m, com dissecação média e associada a Relevos Tabulares; SRAIIB-RT: Superfície Regional de Aplainamento IIB com cotas entre 800 e 1000 m, com dissecação média e associada a Relevos Tabulares.

Fonte: Elaborado pelos autores a partir da base geomorfológica de Goiás e Distrito Federal cedida pelo SIEG (2016).

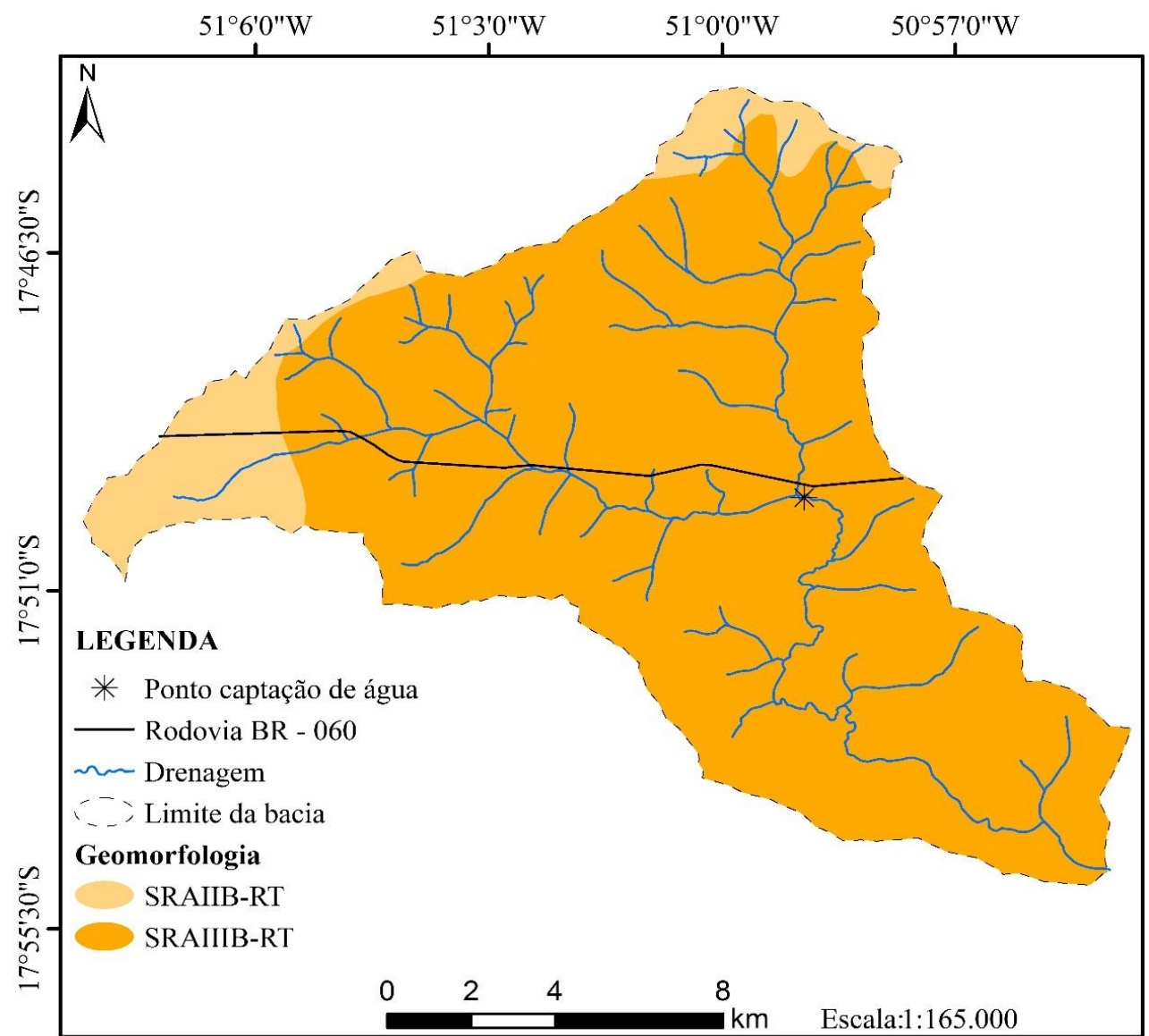

Figura 4. Mapa geomorfológico da bacia do Ribeirão das Abóboras, localizada no município de Rio Verde (GO).

Fonte: Elaborado pelos autores a partir da base geomorfológica de Goiás e Distrito Federal cedida pelo SIEG (2016). 
Dos Santos Alves, W., Scopel, I. y Perini Martins, A. (2017): “Análise da fragilidade ambiental da bacia do Ribeirão das Abóboras, em Rio Verde, Sudoeste de Goiás”, GeoFocus (Artículos), no 19, p. 81-108. ISSN: 1578-5157 http://dx.doi.org/10.21138/GF.556

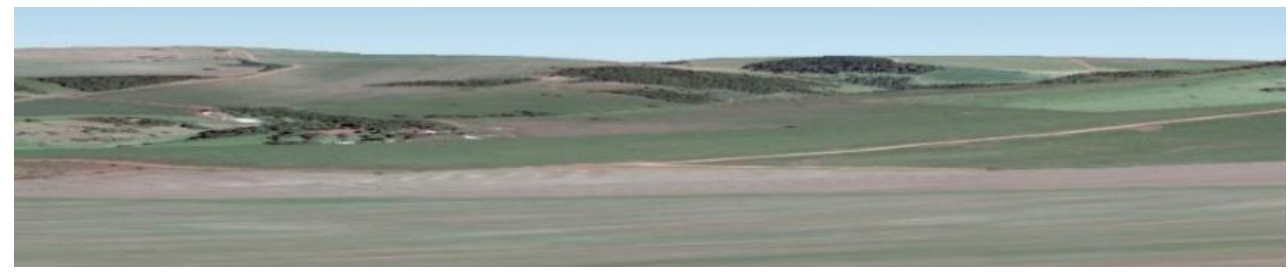

Figura 5. Imagem de Superfície Regional de Aplainamento IIIB com cotas entre 650 e 750 m, com dissecação média e associada a Relevos Tabulares na bacia do Ribeirão das Abóboras, localizada no município de Rio Verde (GO).

Fonte: Google Earth Pro (2016).

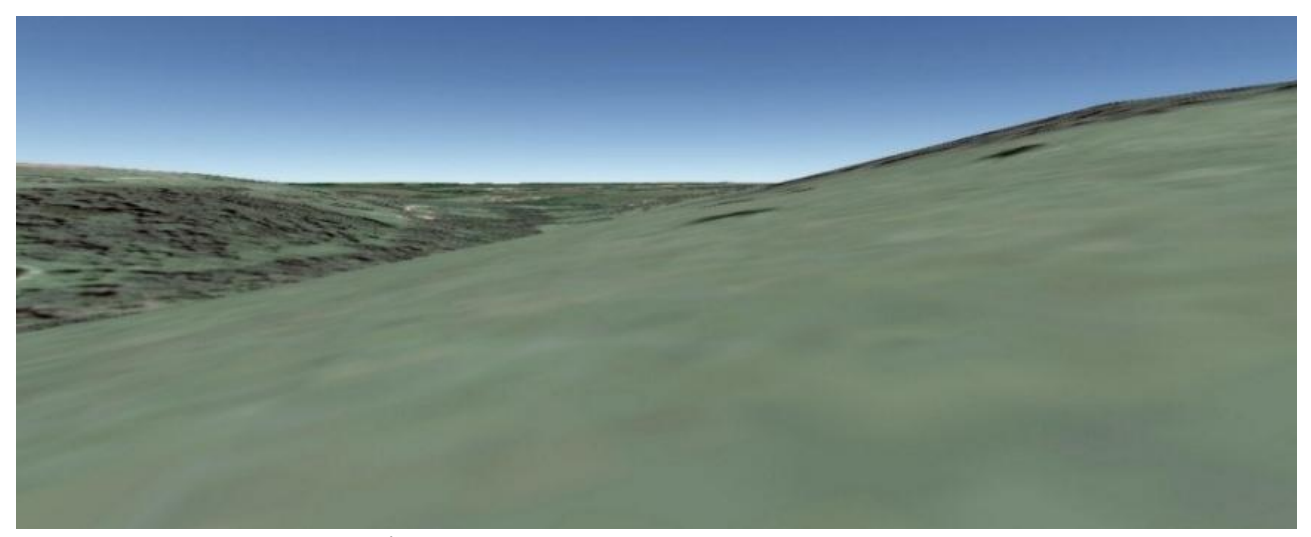

Figura 6. Imagem de Superfície Regional de Aplainamento IIB com cotas entre 800 e 1000 m, com dissecação média e associada a Relevos Tabulares na bacia do Ribeirão das Abóboras, localizada no município de Rio Verde (GO).

Fonte: Google Earth Pro (2016). 
Dos Santos Alves, W., Scopel, I. y Perini Martins, A. (2017): “Análise da fragilidade ambiental da bacia do Ribeirão das Abóboras, em Rio Verde, Sudoeste de Goiás”, GeoFocus (Artículos), no 19, p. 81-108. ISSN: 1578-5157 http://dx.doi.org/10.21138/GF.556

Na Figura 7 é apresentado o mapa temático da bacia do Ribeirão das Abóboras quanto à sua altitude.

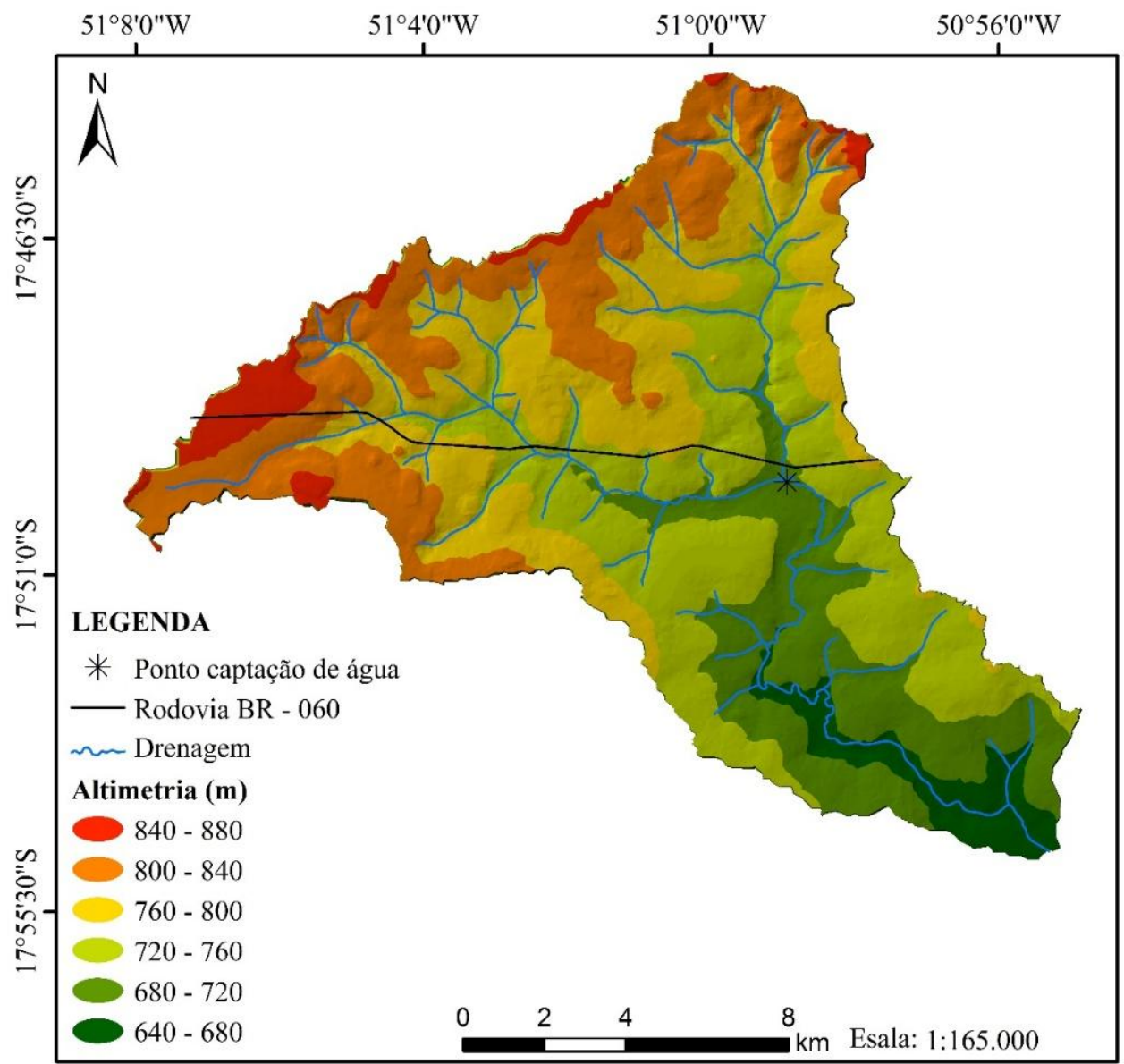

\section{Figura 7. Mapa hipsométrico da bacia do Ribeirão das Abóboras, localizada no município de Rio Verde (GO).}

Fonte: Elaborado pelos autores a partir da base SRTM cedida pelo USGS (2016).

Sendo característico de uma bacia hidrográfica, seu divisor topográfico compõe a região de maiores altitudes observadas, onde ocorrem as zonas de recarga hídrica proveniente das chuvas, enquanto as áreas próximas ao exutório ou foz da bacia hidrográfica apresentam os menores valores de altitude (Figura 7).

O mapa de hipsometria contribui para o entendimento da modelagem e prevenção de movimentos de massa, uma vez que esse processo é influenciado fortemente pela gravidade. Observa-se na Figura 7 que a bacia do Ribeirão das Abóboras apresenta a maior altitude de 880 $\mathrm{m}$, e a menor, de $640 \mathrm{~m}$.

No município de Rio Verde (GO), a vegetação natural predominante é do bioma cerrado, com remanescentes localizados, principalmente, entre os vales fluviais na forma de matas de galeria, associados à maior umidade do ar (Prado et al., 2009). 
Dos Santos Alves, W., Scopel, I. y Perini Martins, A. (2017): “Análise da fragilidade ambiental da bacia do Ribeirão das Abóboras, em Rio Verde, Sudoeste de Goiás”, GeoFocus (Artículos), no 19, p. 81-108. ISSN: 1578-5157 http://dx.doi.org/10.21138/GF.556

\subsection{Bases de dados e processamento}

A partir das seguintes bases foram elaborados o mapa de declividade, solos, uso da terra e cobertura vegetal:

- Imagem Shuttle Radar Topography Mission (SRTM), com resolução espacial de 30 m x 30 m, gerada pela cooperação entre National Aeronautics and Space Administration (NASA) e a National Imagery and Mapping Agency (NIMA), do DOD (Departamento de Defesa) dos Estados Unidos da América e das agências espaciais da Alemanha e da Itália; obtida através de arranjo projetado para coletar medidas tridimensionais da superfície terrestre através de interferometria, a bordo do ônibus espacial Endeavour, entre o período de 11 a 22 de fevereiro de 2000; disponibilizada pelo USGS (2016);

- Mapa de Solos do Plano Diretor da Bacia do Rio Paranaíba, na escala 1:250.000, formato shapefile (shp), geração 01 de março de 2005, gerado pela Universidade Federal de Viçosa (UFV)/Fundação Rural Minas (Ruralminas); modelagem, alimentação do SIG e edição das cartas pela Superintendência de Geologia e Mineração/Secretaria Estadual de Indústria e Comércio (SGM/SIC); disponibilizado pelo SIEG (2016);

- Imagem da órbita/ponto 223/72, com resolução espacial de $30 \mathrm{~m}$ x $30 \mathrm{~m}$, de 2015, do Satélite Landsat 8/Sensor OLI, gerada pela NASA e disponibilizada pelo USGS (2016); e

- Drenagens da Base Cartográfica Vetorial Digital, gerada pela Agência Nacional de Água (ANA), geração de 22 de julho de 2006; revisão de topologia, alimentação, atualizações e edição da carta pela Superintendência de Geologia e Mineração/Secretaria Estadual de Indústria e Comércio (SGM/SIC) e disponibilizada pelo SIEG (2016).

A partir da imagem SRTM foram geradas curvas de nível com equidistância de $5 \mathrm{~m}$, através da ferramenta contour. A partir das curvas de nível foi gerado o arquivo shapefile (shp) com a delimitação da área da bacia, desenhada a partir da seção fluvial do exutório, ou seja, do ponto mais baixo, em direção ao divisor de água.

O shapefile da delimitação da bacia do Ribeirão das Abóboras foi usado para extrair as bases delimitadas da bacia hidrográfica das bases geográficas maiores, com o uso da ferramenta Extract by Masc, no caso das bases de dados em formato raster, e da ferramenta clip, no caso das bases de dados em formato shp.

A partir do SRTM com delimitação da bacia hidrográfica foi gerado o mapa de declividade, com uso das ferramentas Slope, sendo a reclassificação através da ferramenta Reclassify.

Para realizar o estudo da fragilidade ambiental da bacia do Ribeirão das Abóboras foi importante o conhecimento da declividade, dos solos, do uso da terra, cobertura vegetal e do clima. A partir disso, esta pesquisa foi desenvolvida com base na metodologia de Ross (1994), adaptada para as condições físicas da região.

A reclassificação da declividade foi realizada conforme Ross (1994), Ramalho Filho e Beek (1995) e Embrapa (2013), ver Quadro 1. 
Dos Santos Alves, W., Scopel, I. y Perini Martins, A. (2017): “Análise da fragilidade ambiental da bacia do Ribeirão das Abóboras, em Rio Verde, Sudoeste de Goiás", GeoFocus (Artículos), no 19, p. 81-108. ISSN: 1578-5157 http://dx.doi.org/10.21138/GF.556

Quadro 1. Relação entre os graus de fragilidade e as classes de declividade da bacia do Ribeirão das Abóboras, localizada no município de Rio Verde (GO).

\begin{tabular}{|c|c|}
\hline Fragilidade & S ( \%) \\
\hline 1.Muito baixa & $0-3$ \\
\hline 2.Baixa & $3-8$ \\
\hline 3.Média & $8-20$ \\
\hline 4.Alta & $20-45$ \\
\hline 5.Muito alta & $>45$ \\
\hline
\end{tabular}

Fonte: Ross (1994), Ramalho Filho e Beek (1995) e Embrapa (2013).

O mapa de solos foi reclassificado segundo Ross (1994) e Crepani et al. (2001), conforme apresentado no Quadro 2.

Quadro 2. Relação entre os graus de fragilidade e os solos da bacia do Ribeirão das Abóboras, localizada no município de Rio Verde (GO).

\begin{tabular}{|c|c|}
\hline Fragilidade & Tipos de solos \\
\hline 1.Muito baixa & Latossolos \\
\hline 3.Média & Argissolos \\
\hline
\end{tabular}

Fonte: Ross (1994) e Crepani et al. (2001).

As bandas (B) multiespectrais usadas da imagem do Satélite Landsat 8/Sensor OLI foram: B4 (vermelho), B5 (infravermelho próximo) e B6 (natural com remoção atmosférica), sendo a composição das bandas realizadas com o uso da ferramenta Composite Bands. A composição colorida RGB (red, green e blue) das bandas foi R/4, G/5 e B/6. Essas combinações de bandas foram usadas por apresentarem maior aproximação das cores reais. Foi analisada e classificada através da técnica de classificação digital supervisionada, com o uso da ferramenta Interactive Supervised Classification, e reconhecimento de áreas de treinamento no hipermapa Google Earth Pro (2016) e em campo para validação da legenda e mapas preliminares com as classes agricultura, pastagem, Cerrado/matas, eucalipto, área industrial, rodovias, granjas, área urbana e solo exposto/cascalheira.

Em seguida, os diferentes usos da terra e cobertura vegetal da bacia hidrográfica foram reclassificados utilizando a ferramenta Reclassify, convertidos para polígono através da ferramenta Raster to Polygon e quantificados através do comando Calculate Geometry.

Com uso de uma câmera digital, modelo Nikon D5100, foram obtidas fotos em campo para auxiliar nas análises e complementar o trabalho de elaboração do mapa de uso da terra e cobertura vegetal.

Foi usado o software QGIS 2.16 e seu complemento Acuracy para realizar o cruzamento do mapa de uso da terra e cobertura vegetal e amostras kappa e obter a matriz de confusão.

As amostras kappa ou amostras de validação foram obtidas a partir da imagem do Landsat 8/Sensor OLI, uso do Google Earth Pro (2016) e levantamentos de campo. 
Dos Santos Alves, W., Scopel, I. y Perini Martins, A. (2017): “Análise da fragilidade ambiental da bacia do Ribeirão das Abóboras, em Rio Verde, Sudoeste de Goiás”, GeoFocus (Artículos), no 19, p. 81-108. ISSN: 1578-5157 http://dx.doi.org/10.21138/GF.556

A partir da matriz de confusão foi calculado o Índice Kappa na planilha do Excel 2013. O Índice Kappa é um teste estatístico aplicado aos resultados da classificação do uso da terra e cobertura vegetal, que leva em consideração toda a matriz de confusão no seu cálculo, inclusive os elementos de fora da diagonal principal.

Conforme Simões (2001), o Ídice Kappa é calculado através da Equação 1:

$$
K=P 0-P e / 1-P e
$$

Onde, P0 representa a exatidão geral da classificação, soma da coluna diagonal da matriz dividida pelo número total de "pixels" amostrados; Pe, a $\Sigma$ pi $+p+i$, sendo pi+e p+i as proporções marginais da linha i e da coluna i, respectivamente.

O Índice Kappa é recomendado por Rosenfield e Fitzpatrick-Lins (1986), uma vez que utiliza todas as células da matriz de erro, e não apenas os elementos da diagonal, ou seja, mede a probabilidade de um pixel ser corretamente classificado em relação à probabilidade da classificação incorreta.

A qualidade da classificação do uso da terra e cobertura vegetal foi avaliada com base no Quadro 3, onde consta uma escala de valores que definem a qualidade da classificação segundo o Índice Kappa (LANDIS; KOCH, 1977).

Quadro 3. Qualidade da classificação do uso da terra e cobertura vegetal segundo intervalos do Índice Kappa.

\begin{tabular}{|c|c|}
\hline Valor Kappa & Qualidade da classificação \\
\hline$<0,00$ & Péssima \\
\hline $0,00-0,20$ & Ruim \\
\hline $0,20-0,40$ & Razoável \\
\hline $0,40-0,60$ & Boa \\
\hline $0,60-0,80$ & Muito Boa \\
\hline $0,80-1,00$ & Excelente \\
\hline
\end{tabular}

Fonte: Landis; Koch (1977).

A definição das classes de proteção do mapa de uso da terra e cobertura vegetal foi realizada segundo os diferentes tipos de uso da terra e cobertura vegetal adaptado de Ross (1994) e Kawakubo et al. (2005), podendo ser observada no Quadro 4.

Quadro 4. Relação entre os graus de proteção e os diferentes tipos de uso da terra e cobertura vegetal da bacia do Ribeirão das Abóboras, localizada no município de Rio Verde (GO).

\begin{tabular}{|c|c|}
\hline Grau de proteção & Categorias \\
\hline 2.Alta & $\begin{array}{c}\text { Área urbana, industrias, granjas e } \\
\text { Cerrado/matas }\end{array}$ \\
\hline 3.Média & Pastagem e silvicultura \\
\hline 4.Baixa & Culturas anuais \\
\hline 5.Muito baixa & Solo exposto \\
\hline
\end{tabular}

Fonte: Ross (1994) e Kawakubo et al. (2005).

O mapa da declividade e de solos serviram de base para elaboração do mapa de Fragilidade Potencial, natural do ambiente. Os mapas de declividade, de solos e de uso da terra e cobertura vegetal subsidiaram a geração do mapa de Fragilidade Emergente. 
Dos Santos Alves, W., Scopel, I. y Perini Martins, A. (2017): “Análise da fragilidade ambiental da bacia do Ribeirão das Abóboras, em Rio Verde, Sudoeste de Goiás”, GeoFocus (Artículos), no 19, p. 81-108. ISSN: 1578-5157 http://dx.doi.org/10.21138/GF.556

Os mapas foram cruzados na ferramenta Raster Calculator utilizando a Equação 2, para obtenção do mapa de Fragilidade Potencial, e a Equação 3, para obtenção do mapa de Fragilidade Emergente:

$M F P=(M D+M S)$

Onde, MFP é a o mapa de Fragilidade Potencial; MD é o mapa de declividade; e MS é o mapa de solos.

$M F E=\frac{[(3 * M D)+(3 * M S)+(4 * M U)]}{10}$

(3)

Onde, MFE é o mapa de Fragilidade Emergente; MD, mapa de declividade; e MU, mapa de uso da terra e cobertura vegetal.

Na geração do mapa de Fragilidade Emergente, foi dado peso 3 para o mapa de declividade e mapa de solos e peso 4 para o mapa de uso da terra e cobertura vegetal, levando em consideração um maior peso para as ações antrópicas na bacia hidrográfica.

Depois de cruzados os mapas, estes foram reclassificados em 5 classes, conforme proposta de Ross (2004), e convertidos para polígonos, com o uso da ferramenta Raster to Polygon, para em seguida obter a área $\left(\mathrm{km}^{2}\right)$ correspondente a cada classe de fragilidade na tabela de atributos.

Todas as ferramentas de geoprocessamento supracitadas, com exceção da usada na validação da classificação do mapa de uso da terra e cobertura vegetal, são do software ArcGIS $10.1^{\circledR}$.

O valor de erosividade da chuva (fator $R$ ) foi obtido com o uso da Equação 4 proposta por Wischmeier e Smith (1978), com adaptação para as condições brasileiras por Lombardi e Moldenhauer (1977) apud Bertoni e Lombardi (1999):

$E I 30=67,355\left(r^{2} / P\right)^{0,85}$

Onde, EI30 é a média mensal do índice de erosividade em MJ.mm/(ha.h); r, a média dos totais mensais de precipitação em mm; e Pp, a média dos totais anuais de precipitação em mm.

A área de estudo apresenta duas estações bem definidas, uma seca, de maio a outubro, e outra chuvosa, de novembro a abril, sendo caracterizada como mesotérmico úmido, com temperaturas amenas durante o inverno e calor no verão e, principalmente, na primavera. Nas estações outono-inverno são registradas as menores temperaturas, que podem variar de $6{ }^{\circ} \mathrm{C}$ à $15^{\circ} \mathrm{C}$. A temperatura média anual varia entre $20^{\circ} \mathrm{C}$ e $25^{\circ} \mathrm{C}$ (FERREIRA, 2010).

Em Rio Verde (GO), a precipitação média anual nos anos de 1996 a 2015 foi de 1615,1 $\mathrm{mm}$, e os maiores níveis pluviométricos ocorram nos meses de outubro a abril e os menores, de maio a setembro, conforme dados observados na estação 83470 de Rio Verde (GO) obtidos no Banco de Dados Meteorológicos para Ensino e Pesquisa (BDMEP, 2016). As médias mensais são apresentadas na Figura 8.

A média dos totais mensais de precipitação em Rio Verde (GO) foi de $134,59 \mathrm{~mm}$, e a média dos totais anuais, de 1615,08 mm, observados de um período de 20 anos (1996 a 2015) da estação 83470 de Rio Verde (GO), na página do BDMEP (2016). 
Dos Santos Alves, W., Scopel, I. y Perini Martins, A. (2017): “Análise da fragilidade ambiental da bacia do Ribeirão das Abóboras, em Rio Verde, Sudoeste de Goiás", GeoFocus (Artículos), no 19, p. 81-108. ISSN: 1578-5157 http://dx.doi.org/10.21138/GF.556

Devido em muitos meses anteriores ao ano de 1996 não terem sido registradas precipitações pela estação pluviométrica supracitada, optou-se em usar os dados de precipitação a partir do ano desta data.

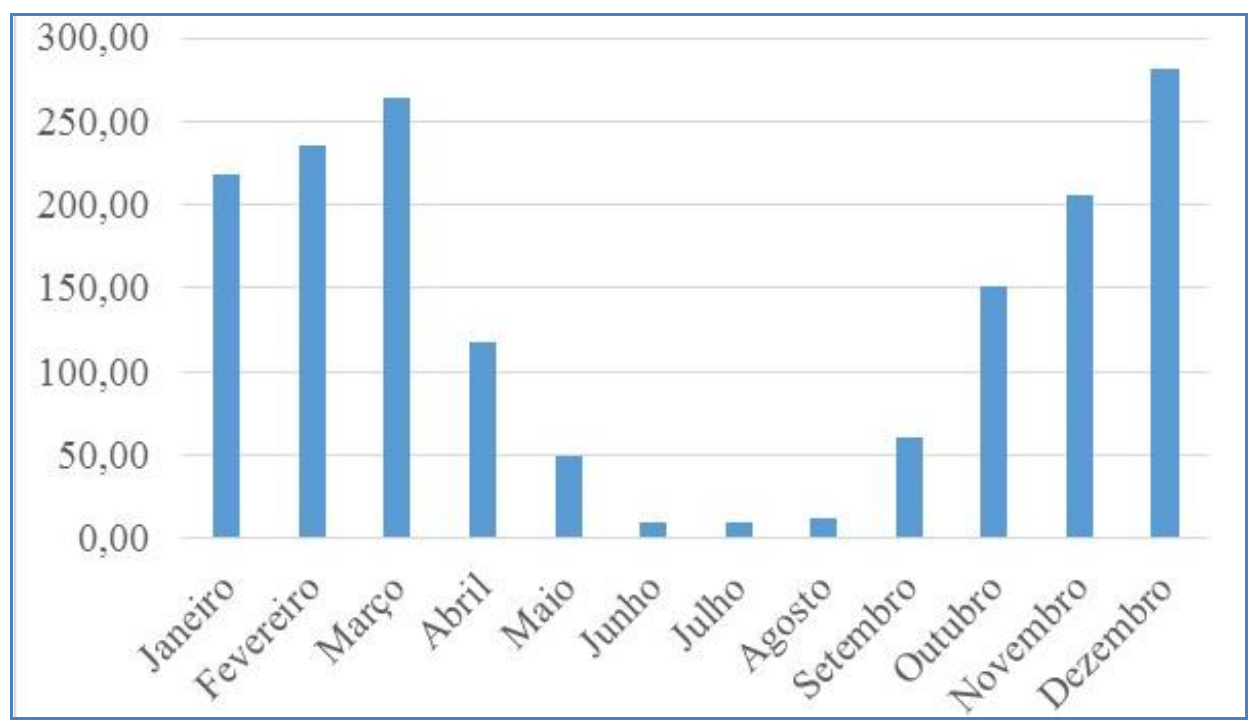

Figura 8. Gráfico da média mensal de precipitação $(\mathrm{mm})$ de janeiro de 1996 a dezembro de 2015, no município de Rio Verde (GO).

Fonte: Elaborado pelos autores a partir de dados cedidos pelo BDMEP (2016).

No intuito de classificar a bacia hidrográfica quanto à erosividade da chuva, o valor obtido em MJ $\cdot \mathrm{mm} \cdot \mathrm{hă}^{-1} \cdot \mathrm{h}^{-1} \cdot \mathrm{ano}^{-1}$ foi transformado para $\mathrm{tn} \cdot \mathrm{mm} \cdot \mathrm{ha}^{-1} \cdot \mathrm{ano}^{-1}$, ou seja, o valor inicial foi dividido por 9,81, sendo convertido do sistema métrico internacional para o sistema métrico decimal, conforme observado em Cabral et al. (2011).

Os valores de erosividade obtidos foram comparados com as classes propostas por Carvalho (1994), conforme o Quadro 4.

Quadro 4. Classes de erosividade da chuva (média anual).

\begin{tabular}{|c|c|}
\hline Classes de erosividade & Erosividade (tn.mm.ha $^{-1}$.ano $^{-\mathbf{1}}$ ) \\
\hline 1.Muito baixa & $\mathrm{R}<250$ \\
\hline 2.Baixa & $250<\mathrm{R}<500$ \\
\hline 3.Média & $500<\mathrm{R}<750$ \\
\hline 4.Alta & $750<\mathrm{R}<1000$ \\
\hline 5.Muito alta & $\mathrm{R}>1000$ \\
\hline
\end{tabular}

Fonte: Carvalho (1994).

\section{Resultados e discussão}

O valor de erosividade obtido corresponde a 643,04 tn.ha ${ }^{-1}$.ano ${ }^{-1}$ e este resultado, conforme a proposta de Carvalho (1994), apresentada no Quadro 4, classifica a bacia do Ribeirão das Abóboras como de médio risco de erosividade.

Quanto a declividade, conforme a classificação de declividade da Embrapa (2013), a área de estudo apresenta predominância de relevo suave-ondulado (53,67 \%), seguido principalmente 
Dos Santos Alves, W., Scopel, I. y Perini Martins, A. (2017): “Análise da fragilidade ambiental da bacia do Ribeirão das Abóboras, em Rio Verde, Sudoeste de Goiás”, GeoFocus (Artículos), no 19, p. 81-108. ISSN: 1578-5157 http://dx.doi.org/10.21138/GF.556

de plano $(28,39 \%)$ e ondulado $(17,32 \%)$, sendo favoráveis a produção agrícola (Tabela 3; Figura 9).

As áreas com declividade superior a $8 \%$ são aptas para agricultura moderna desde que sejam usadas técnicas de manejo e conservação do solo e da água adequadas, e atendidas as leis ambientais vigentes.

Tabela 3. Classes de fragilidade para declividade na bacia do Ribeirão das Abóboras, localizada no município de Rio Verde (GO).

\begin{tabular}{cccc}
\hline Fragilidade & $\mathbf{S ~ ( \% )}$ & $\mathbf{k m}^{\mathbf{2}}$ & $\mathbf{\%}$ \\
\hline 1.Muito baixa & $0-3$ & 56,53 & 28,39 \\
2.Baixa & $3-8$ & 106,86 & 53,67 \\
3.Média & $8-20$ & 34,48 & 17,32 \\
4.Alta & $20-45$ & 1,21 & 0,61 \\
5.Muito alta & $>45$ & 0,02 & 0,01 \\
\hline Total & - & 199,1 & 100
\end{tabular}

Fonte: Elaborado pelos autores.

A área da bacia hidrográfica apresenta os cinco graus de fragilidade para a declividade, sendo predominante a classe com fragilidade baixa, correspondendo a 53,67\% da área total, seguida pela classe muito baixa, $28,39 \%$, classe média, $17,32 \%$, classe alta, $0,61 \%$, e classe muito alta, 0,01\%, conforme pode ser observado na Tabela 3, com espacialização na Figura 9.

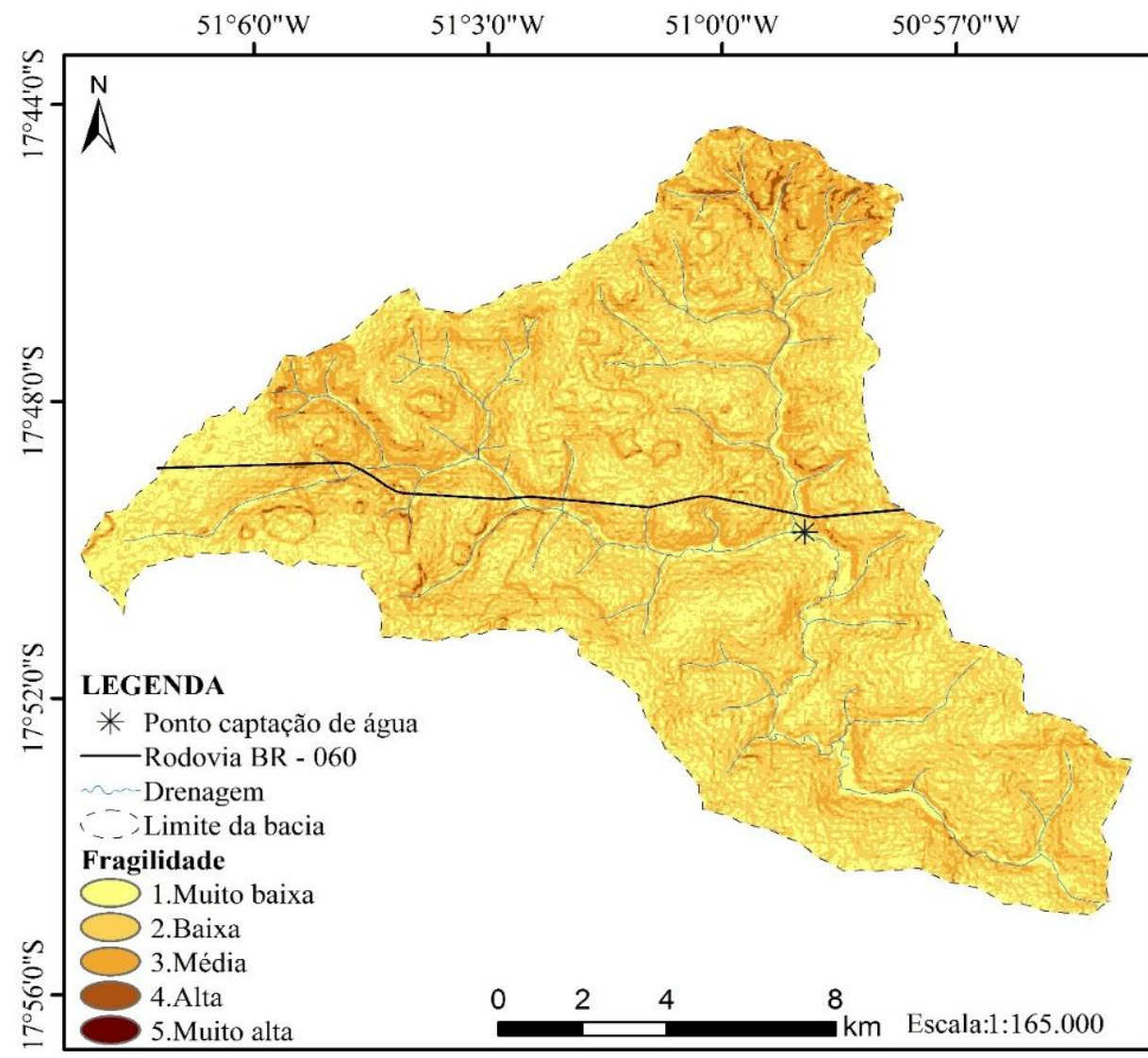

Figura 9. Fragilidade para a declividade na bacia do Ribeirão das Abóboras, localizada no município de Rio Verde (GO).

Fonte: Elaborado pelos autores a partir da base SRTM cedida pelo USGS (2016). 
Dos Santos Alves, W., Scopel, I. y Perini Martins, A. (2017): “Análise da fragilidade ambiental da bacia do Ribeirão das Abóboras, em Rio Verde, Sudoeste de Goiás”, GeoFocus (Artículos), no 19, p. 81-108. ISSN: 1578-5157 http://dx.doi.org/10.21138/GF.556

Observam-se os maiores graus de fragilidade da declividade próximos aos cursos hídricos, onde as Áreas de Preservação Permanentes devem ser mantidas cobertas por vegetação nativa, conforme a Lei ${ }^{\circ}$ 12.621, de 25 de maio de 2012 (Novo Código Florestal Brasileiro), para preservar os recursos hídricos, a paisagem, a estabilidade geológica e a biodiversidade, facilitar o fluxo gênico de fauna e flora, proteger os solos e assegurar o bem-estar do ser humano.

Na tabela 4 e Figura 10 observam-se as classes de solos na área de estudo.

Tabela 4. Unidade de mapeamento de solos da bacia do Ribeirão das Abóboras, localizada no município de Rio Verde (GO).

\begin{tabular}{ccc}
\hline Classe & $\mathbf{k m}^{\mathbf{2}}$ & \% \\
\hline LVd1 & 96,36 & 48,39 \\
LVd11 & 72,09 & 36,21 \\
LVd16 & 21,50 & 10,80 \\
PVd12 & 9,15 & 4,60 \\
\hline Total & 199,1 & 100
\end{tabular}

LVd1: Latossolo Vermelho Distrófico, horizonte A moderado ou proeminente, textura muito argilosa ou argilosa; LVd11: Latossolo Vermelho + Latossolo Vermelho-amarelo, ambos textura argilosa + Latossolo Vermelho textura média, todos Distróficos, horizonte A moderado; LVd16: Latossolo Vermelho +

Latossolo Vermelho-amarelo, ambos textura média + Neossolo Quartzarênico, todos Distróficos e horizonte A moderado; PVd12: Argissolos Vermelhos Distróficos + Argissolos Vermelhos Eutróficos + Latossolos Vermelhos Distroférricos.

Fonte: Elaborado pelos autores a partir da base pedológica de Goiás cedida pelo SIEG (2016). 
Dos Santos Alves, W., Scopel, I. y Perini Martins, A. (2017): “Análise da fragilidade ambiental da bacia do Ribeirão das Abóboras, em Rio Verde, Sudoeste de Goiás”, GeoFocus (Artículos), no 19, p. 81-108. ISSN: 1578-5157 http://dx.doi.org/10.21138/GF.556

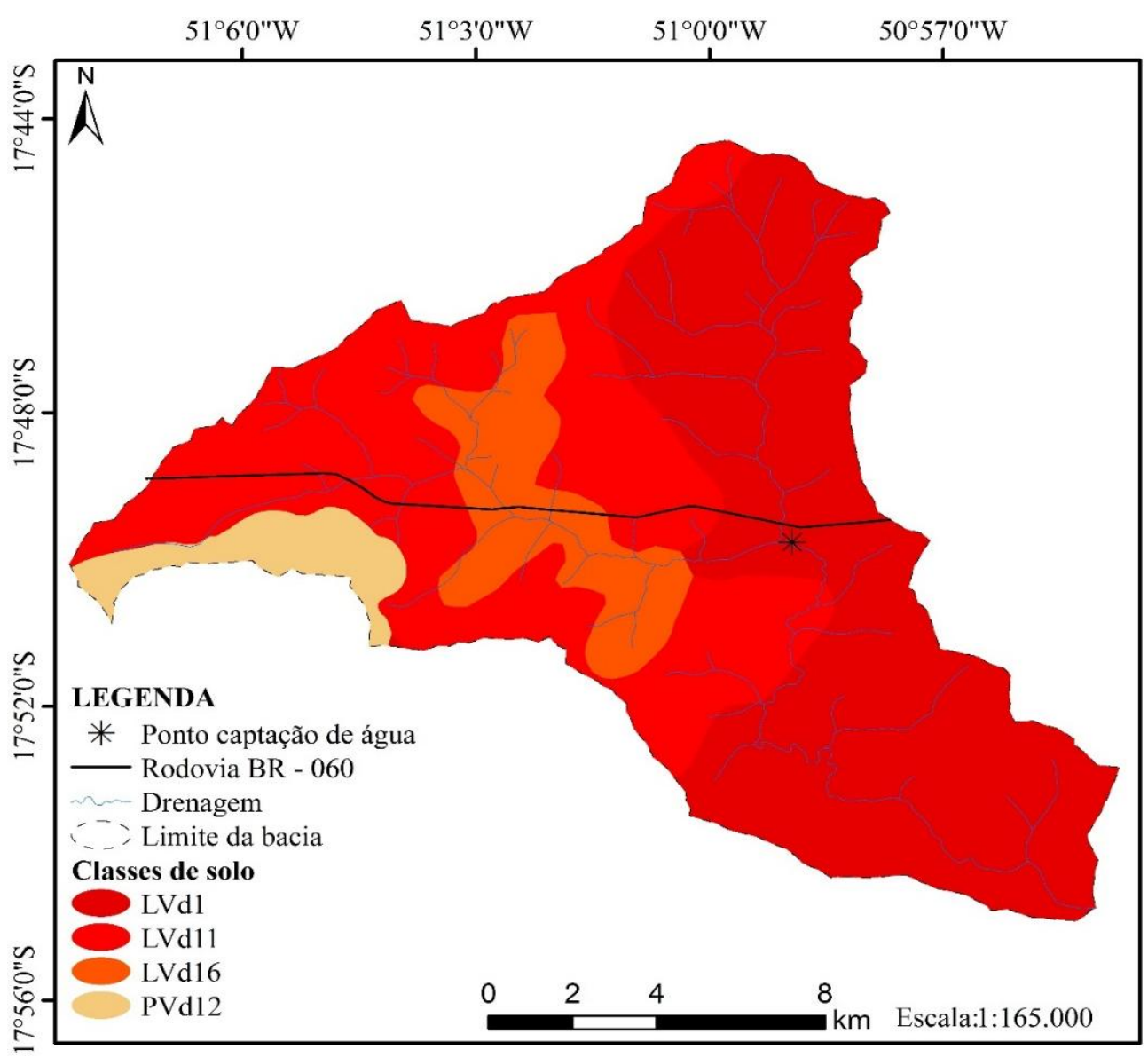

Figura 10. Unidade de mapeamento de solos da bacia do Ribeirão das Abóboras, localizada no município de Rio Verde (GO).

Fonte: Elaborado pelos autores a partir do mapa de solos cedido pelo SIEG (2016).

A área da bacia do Ribeirão das Abóboras apresenta quatro associações de solos (Tabela 4; Figura 10), conforme Embrapa (2013) e mapa de solos do Plano Diretor da Bacia do Rio Paranaíba cedido pelo SIEG (2016):

- Latossolo Vermelho Distrófico, horizonte A moderado ou proeminente, textura muito argilosa ou argilosa, sendo a maior área (LVd1);

- Latossolo Vermelho + Latossolo Vermelho-amarelo, ambos textura argilosa + Latossolo Vermelho textura média, todos Distróficos, horizonte A moderado, sendo a segunda maior extensão (LVd11);

- Latossolo Vermelho + Latossolo Vermelho-amarelo, ambos textura média + Neossolo Quartzarênico, todos Distróficos e horizonte A moderado, terceira maior extensão (LVd16); e

- Argissolos Vermelhos Distróficos + Argissolos Vermelhos Eutróficos + Latossolos Vermelhos Distroférricos, com menor extensão na bacia hidrográfica (PVd12).

Predominam na bacia hidrográfica, segundo Embrapa (2013) e SIEG (2016), os Latossolos, sendo estes profundos, bem drenados, com alto grau de intemperização, ocorrendo 


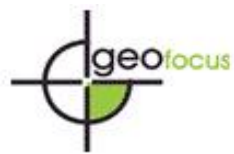

Dos Santos Alves, W., Scopel, I. y Perini Martins, A. (2017): “Análise da fragilidade ambiental da bacia do Ribeirão das Abóboras, em Rio Verde, Sudoeste de Goiás”, GeoFocus (Artículos), no 19, p. 81-108. ISSN: 1578-5157 http://dx.doi.org/10.21138/GF.556

em relevos planos e suavemente-ondulados, com propriedades físicas favoráveis à produção agropecuária (Tabela 4; Figura 10).

Os Argissolos aparecem em menor extensão (Tabela 4; Figura 10). Ocorrem em diferentes condições climáticas e de material de origem. Sua ocorrência está relacionada, em sua grande maioria, a paisagens de relevos mais acidentados e dissecados, com superfícies menos suaves (Embrapa, 2017).

Para os tipos de solos, notam-se (Tabela 5; Figura 11) duas classes de fragilidade na bacia hidrográfica, sendo predominante a classe muito baixa com 95,41\% da área total e em seguida a classe de média fragilidade com 4,59\%.

A média fragilidade observada na bacia hidrográfica quanto ao tipo de solo com 4,59 \% da área total é em decorrência das características dos Argissolos (Tabela 5; Figura 11).

Os Argissolos Distróficos apresentam baixa fertilidade natural e acidez elevada; sendo os Eutróficos naturalmente mais ricos em elementos (bases) essenciais às plantas como cálcio, magnésio e potássio, com boas condições físicas e em relevos mais suaves apresentam maior potencial para uso agrícola (EMBRAPA, 2017).

Os Argissolos tendem a ser mais suscetíveis aos processos erosivos devido à relação textural presente nestes solos, que implica em diferenças de infiltração dos horizontes superficiais e subsuperficiais; e de acordo com suas limitações supracitadas, a sua utilização exige um manejo adequado com a adoção de correção, adubação e de práticas conservacionistas para o controle da erosão (EMBRAPA, 2017).

Tabela 5. Classes de fragilidade para os tipos de solo na bacia do Ribeirão das Abóboras, localizada no município de Rio Verde (GO).

\begin{tabular}{cccc}
\hline Fragilidade & Tipos de solos & $\mathbf{k m}^{\mathbf{2}}$ & $\mathbf{\%}$ \\
\hline 1.Muito baixa & Latossolos & 189,96 & 95,41 \\
3.Média & Argissolos & 9,14 & 4,59 \\
\hline Total & - & 199,1 & 100 \\
\hline
\end{tabular}

Fonte: Elaborado pelos autores a partir do mapa de solos cedido pelo SIEG (2016).

O resultado do Índice Kappa foi de 0,96, para o mapa de uso da terra e cobertura vegetal no ano de 2015. Este resultado representa excelente grau de aceitação da classificação do uso da terra e cobertura vegetal (LANDIS; KOCH, 1977; CONGALTON; GREEN, 2009). 
Dos Santos Alves, W., Scopel, I. y Perini Martins, A. (2017): “Análise da fragilidade ambiental da bacia do Ribeirão das Abóboras, em Rio Verde, Sudoeste de Goiás", GeoFocus (Artículos), no 19, p. 81-108. ISSN: 1578-5157 http://dx.doi.org/10.21138/GF.556

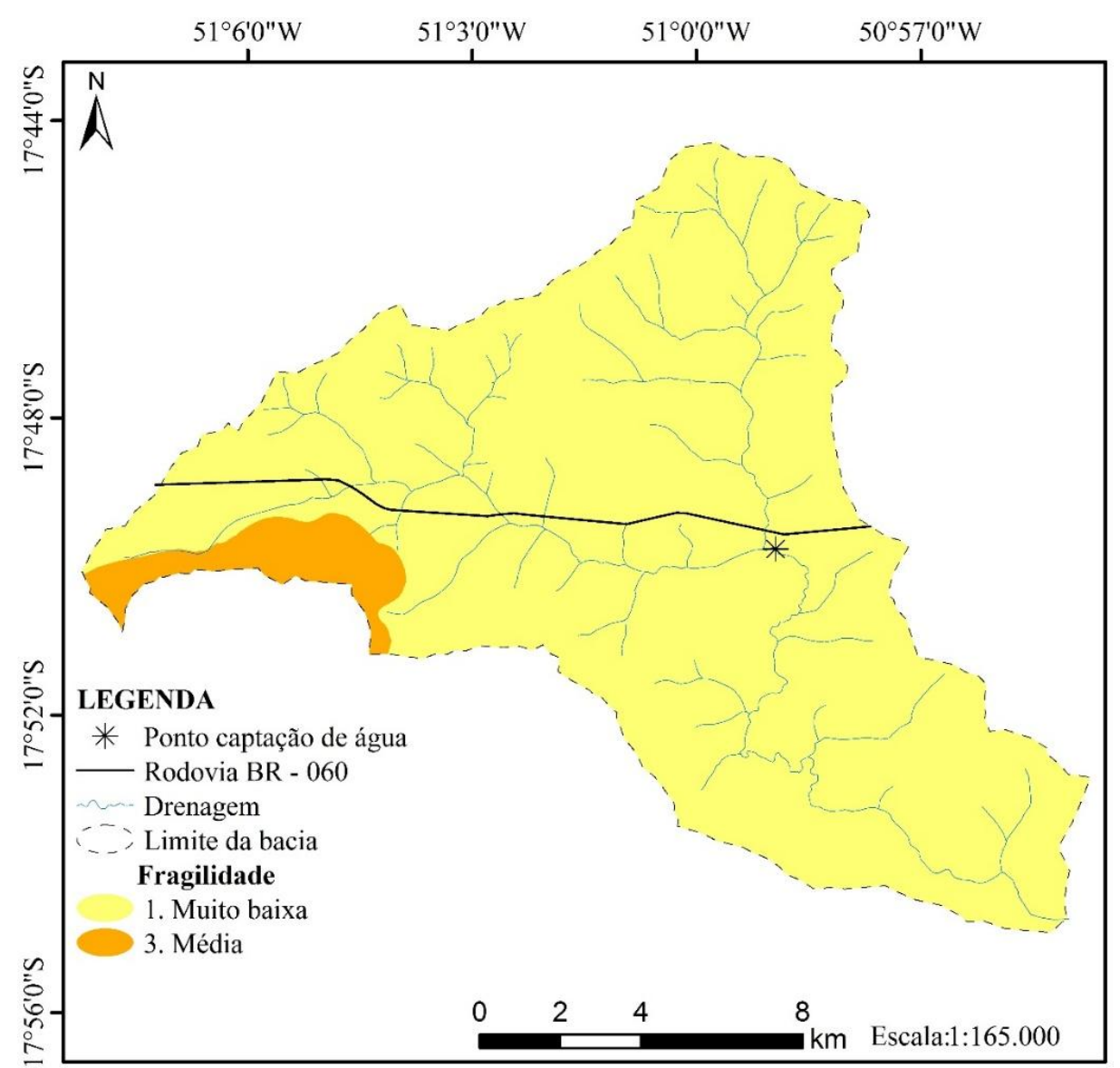

Figura 11. Fragilidade para os tipos de solo na bacia do Ribeirão das Abóboras, localizada no município de Rio Verde (GO).

Fonte: Elaborado pelos autores a partir do mapa de solos cedido pelo SIEG (2016).

Os resultados do uso da terra e cobertura vegetal na bacia do Ribeirão das Abóboras são apresentados na Tabela 6, com espacialização na Figura 12.

Tabela 6. Uso da terra e cobertura vegetal no ano de 2015, na bacia do Ribeirão das Abóboras, localizada no município de Rio Verde (GO).

\begin{tabular}{ccc}
\hline Categorias & \multicolumn{2}{c}{ Ano 2015 } \\
\cline { 2 - 3 } & $\mathrm{km}^{2}$ & $\% 2,00$ \\
Agricultura & 123,45 & 19,60 \\
Cerrado/matas & 39,03 & 11,94 \\
Pastagem & 23,77 & 3,97 \\
Silvicultura/eucalipto & 7,90 & 1,17 \\
Área industrial & 2,33 & 0,51 \\
Rodovias BR-060, GO-174 e anel viário & 1,02 & 0,43 \\
Granjas de avicultura e suinocultura & 0,85 & 0,25 \\
Área urbanizada & 0,50 & 0,13 \\
Solo exposto/cascalheira & 0,25 & 100 \\
\hline Área total & 199,10 &
\end{tabular}

Fonte: Adaptado de Alves et al. (2016). 
Dos Santos Alves, W., Scopel, I. y Perini Martins, A. (2017): “Análise da fragilidade ambiental da bacia do Ribeirão das Abóboras, em Rio Verde, Sudoeste de Goiás”, GeoFocus (Artículos), no 19, p. 81-108. ISSN: 1578-5157 http://dx.doi.org/10.21138/GF.556

Nota-se que a bacia do Ribeirão das Abóboras é ocupada predominantemente por agricultura com $62,00 \%$. As principais culturas agrícolas são soja e milho safrinha, sendo a soja cultivada de outubro a novembro, e o milho safrinha, de janeiro a abril.

A área de Cerrado/matas (ciliar e de galeria) ocupa a segunda maior extensão da bacia hidrográfica com $19,60 \%$, sendo este remanescente composto principalmente por Área de Preservação Permanente, notadamente nas margens dos cursos hídricos, e Reserva Legal.

A pastagem corresponde a terceira maior área com 11,94\%, sendo observadas a pecuária extensiva e intensiva, principalmente nas superfícies com declividades acentuadas, onde a mecanização para o cultivo agrícola é impossibilitado.

A silvicultura, 3,97 \% da área total da bacia hidrográfica, é voltada para a produção de eucalipto com a finalidade de complementar a demanda energética da BRF e da Cooperativa Agroindustrial dos Produtores Rurais do Sudoeste Goiano (COMIGO), além de ser usado também como barreira de proteção das granjas instaladas na área de estudo.

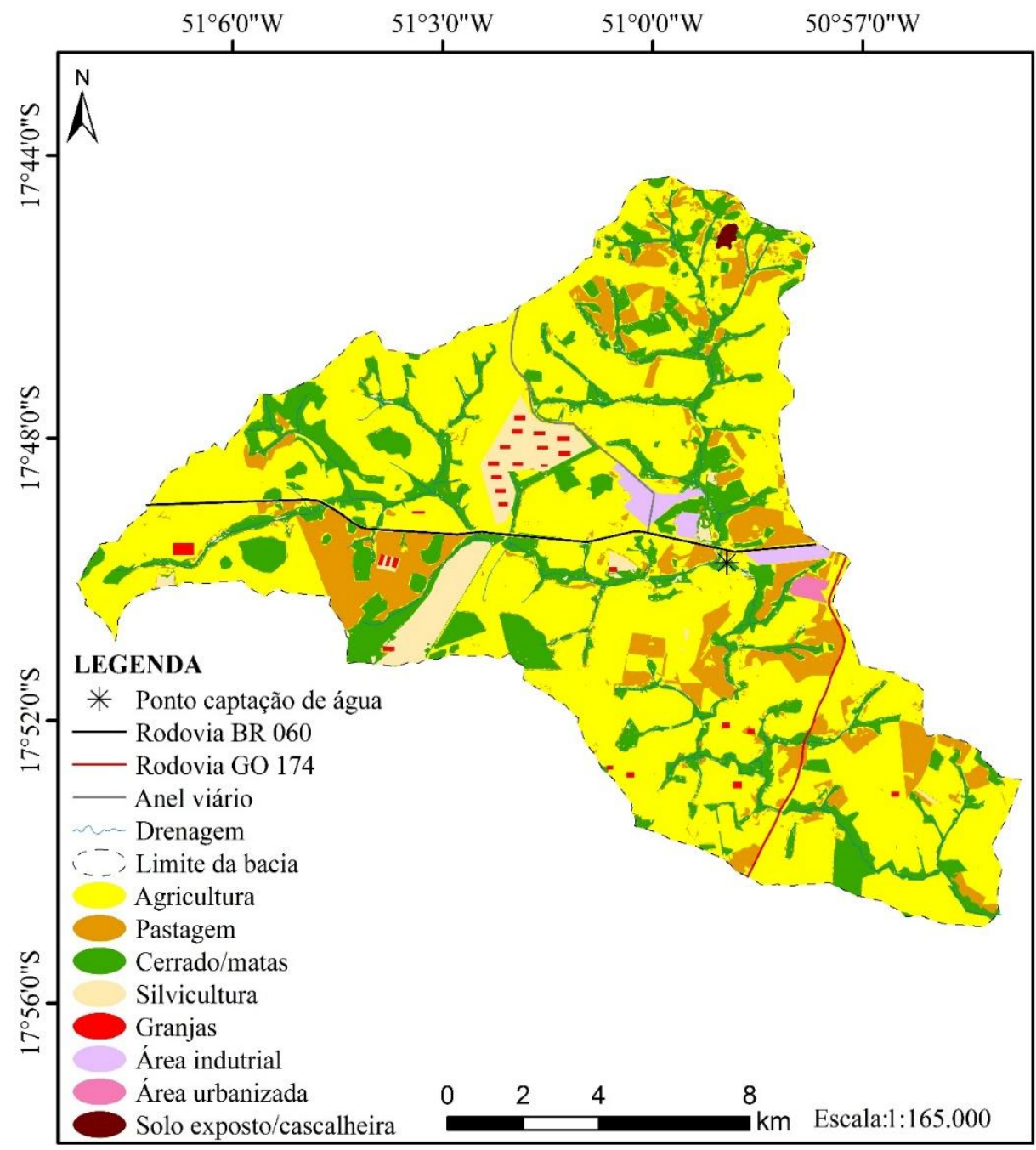

Figura 12. Uso da terra e cobertura vegetal para o ano de 2015, na bacia do Ribeirão das Abóboras, localizada no município de Rio Verde (GO).

Fonte: Elaborado pelos autores a partir de bases geográficas cedidas pelo USGS (2016) e SIEG (2016). 
Dos Santos Alves, W., Scopel, I. y Perini Martins, A. (2017): “Análise da fragilidade ambiental da bacia do Ribeirão das Abóboras, em Rio Verde, Sudoeste de Goiás”, GeoFocus (Artículos), no 19, p. 81-108. ISSN: 1578-5157 http://dx.doi.org/10.21138/GF.556

A área industrial com $1,17 \%$, onde está inserida a principal agroindústria do município, a unidade de Rio Verde da BFR, classificada como uma das maiores companhias de alimentos do mundo.

As rodovias com 0,51\%, sendo as principais a Rodovia BR-060 e a Rodovia GO-174, são usadas para o escoamento das produções agropecuária e agroindustrial, dentre outras finalidades.

As granjas instaladas na bacia hidrográfica ocupam uma extensão de $0,43 \%$, sendo destinadas à produção de matéria prima (aves e suínos) para os processos produtivos da BRF.

Com menor representatividades, observam-se: área urbanizada com 0,25\%; e solo exposto/cascalheira com $0,13 \%$, sendo esta uma área antiga, onde é explorado cascalho usado em benfeitorias e expansão urbana de Rio Verde (GO).

Observam-se quatro classes de grau de proteção da bacia hidrográfica, a mais representativa é a classe baixa com $62,41 \%$, seguida da classe alta com $21,43 \%$, média com $16,03 \%$, e muito baixa com $0,13 \%$ (Tabela 7). Estes graus de proteção dos solos estão espacializados na Figura 13.

Tabela 7. Classes de proteção para as categorias de uso da terra e cobertura vegetal na bacia do Ribeirão das Abóboras, localizada no município de Rio Verde (GO).

\begin{tabular}{cccc}
\hline Grau de proteção & Categorias & $\mathbf{k m}^{\mathbf{2}}$ & $\mathbf{\%}$ \\
\hline 2.Alta & Área urbana, industrial, granjas & 42,67 & 21,43 \\
& e Cerrado/matas. & 31,92 & 16,03 \\
3.Média & Pastagem e silvicultura. & 124,26 & 62,41 \\
4.Baixa & Culturas anuais. & 0,25 & 0,13 \\
5.Muito baixa & Solo exposto. & 199,1 & 100 \\
\hline Área total & - &
\end{tabular}

A fragilidade ambiental potencial da bacia hidrográfica apresenta com predominância a classe baixa com $72,73 \%$, seguida pela classe muito baixa com $23,40 \%$ e pela alta com $3,87 \%$, conforme visualiza-se na Tabela 8 e Figura 14.

Os resultados para a fragilidade potencial nos mostram que a bacia hidrográfica apresenta um potencial à utilização significativo. Entretanto apontam que o uso da terra e cobertura vegetal devem ser com cuidado em razão de $7,72 \mathrm{~km}^{2}$ apresentarem naturalmente índice alto de fragilidade.

Tabela 8. Classes de fragilidade potencial na bacia do Ribeirão das Abóboras, localizada no município de Rio Verde (GO).

\begin{tabular}{ccc}
\hline Fragilidade & $\mathbf{k m}^{\mathbf{2}}$ & $\mathbf{\%}$ \\
\hline 1.Muito baixa & 46,58 & 23,40 \\
2.Baixa & 144,80 & 72,73 \\
4.Alta & 7,72 & 3,87 \\
\hline Total & 199,1 & 100 \\
\hline
\end{tabular}

Fonte: Elaborado pelos autores. 
Dos Santos Alves, W., Scopel, I. y Perini Martins, A. (2017): “Análise da fragilidade ambiental da bacia do Ribeirão das Abóboras, em Rio Verde, Sudoeste de Goiás”, GeoFocus (Artículos), no 19, p. 81-108. ISSN: 1578-5157 http://dx.doi.org/10.21138/GF.556

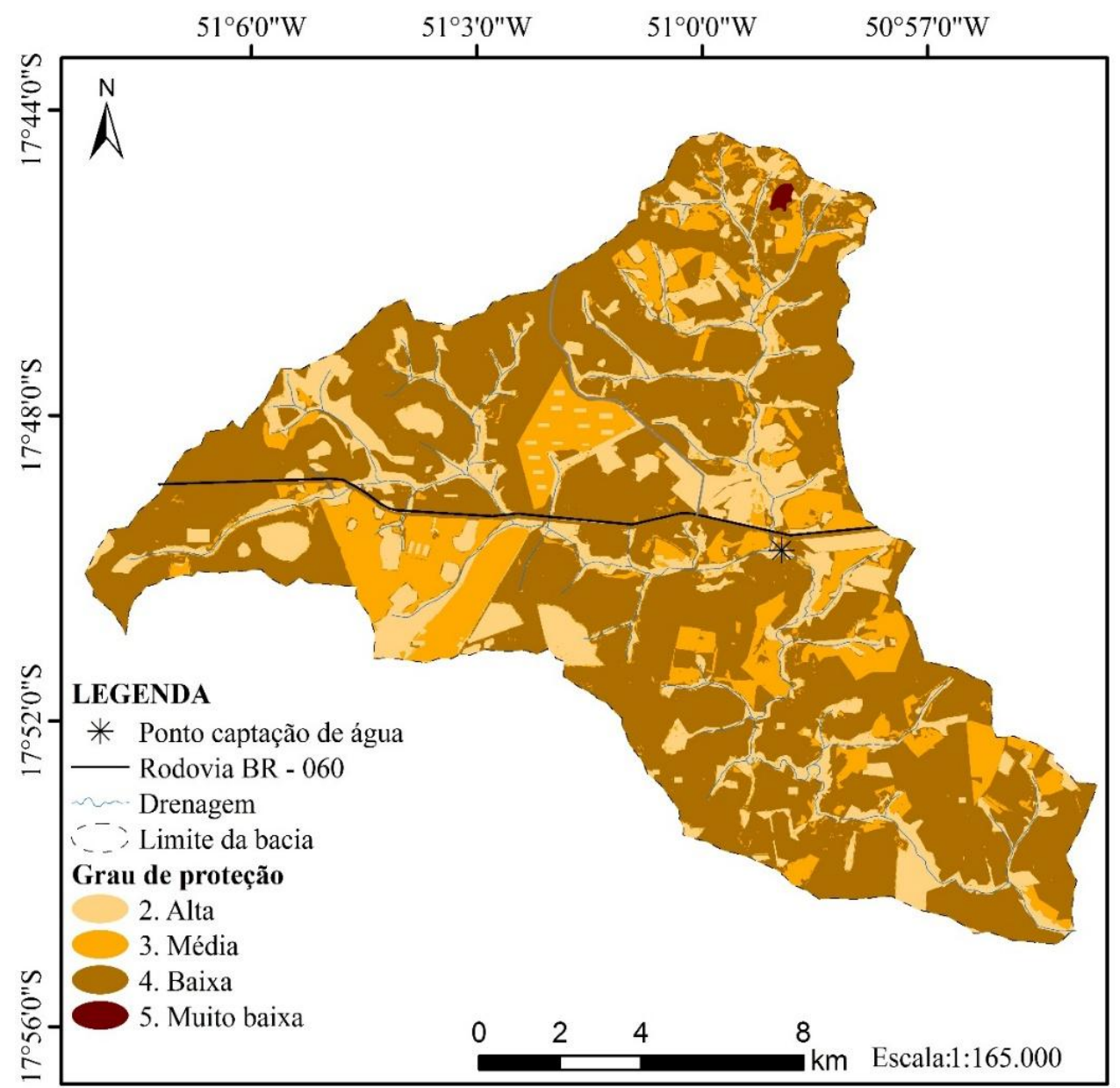

Figura 13. Classes de proteção para os diferentes usos da terra e cobertura vegetal na bacia do Ribeirão das Abóboras, localizada no município de Rio Verde (GO).

Fonte: Elaborado pelos autores a partir de bases geográficas cedidas pelo USGS (2016) e SIEG (2016).

Os resultados obtidos para a classificação da fragilidade ambiental emergente foram, em ordem de tamanho maior para menor, média fragilidade com 78,96\% da área, baixa fragilidade com $20,60 \%$ e alto com $0,35 \%$, ver Tabela 9 e Figura 15.

A fragilidade classificada como alta é devido as declividades mais acentuadas e aos Argissolos serem favoráveis à ocorrência dos processos erosivos, como mencionado.

As características da declividade, dos solos, do uso da terra e cobertura vegetal na bacia do Ribeirão das Abóboras, em conjunto com a erosividade e associadas ao manejo inadequado, provocam prejuízos ambientais (Figura 16; Figura 17; Figura 18), podendo estes serem irreversíveis. 
Dos Santos Alves, W., Scopel, I. y Perini Martins, A. (2017): “Análise da fragilidade ambiental da bacia do Ribeirão das Abóboras, em Rio Verde, Sudoeste de Goiás”, GeoFocus (Artículos), no 19, p. 81-108. ISSN: 1578-5157 http://dx.doi.org/10.21138/GF.556

Tabela 9. Classes de fragilidade ambiental emergente na bacia do Ribeirão das Abóboras, localizada no município de Rio Verde (GO).

\begin{tabular}{ccc}
\hline Fragilidade & $\mathbf{k m}^{\mathbf{2}}$ & $\mathbf{\%}$ \\
\hline 2.Baixa & 41,19 & 20,69 \\
3.Média & 157,21 & 78,96 \\
4.Alta & 0,70 & 0,35 \\
\hline Total & 199,1 & 100 \\
\hline
\end{tabular}

Fonte: Elaborado pelos autores.

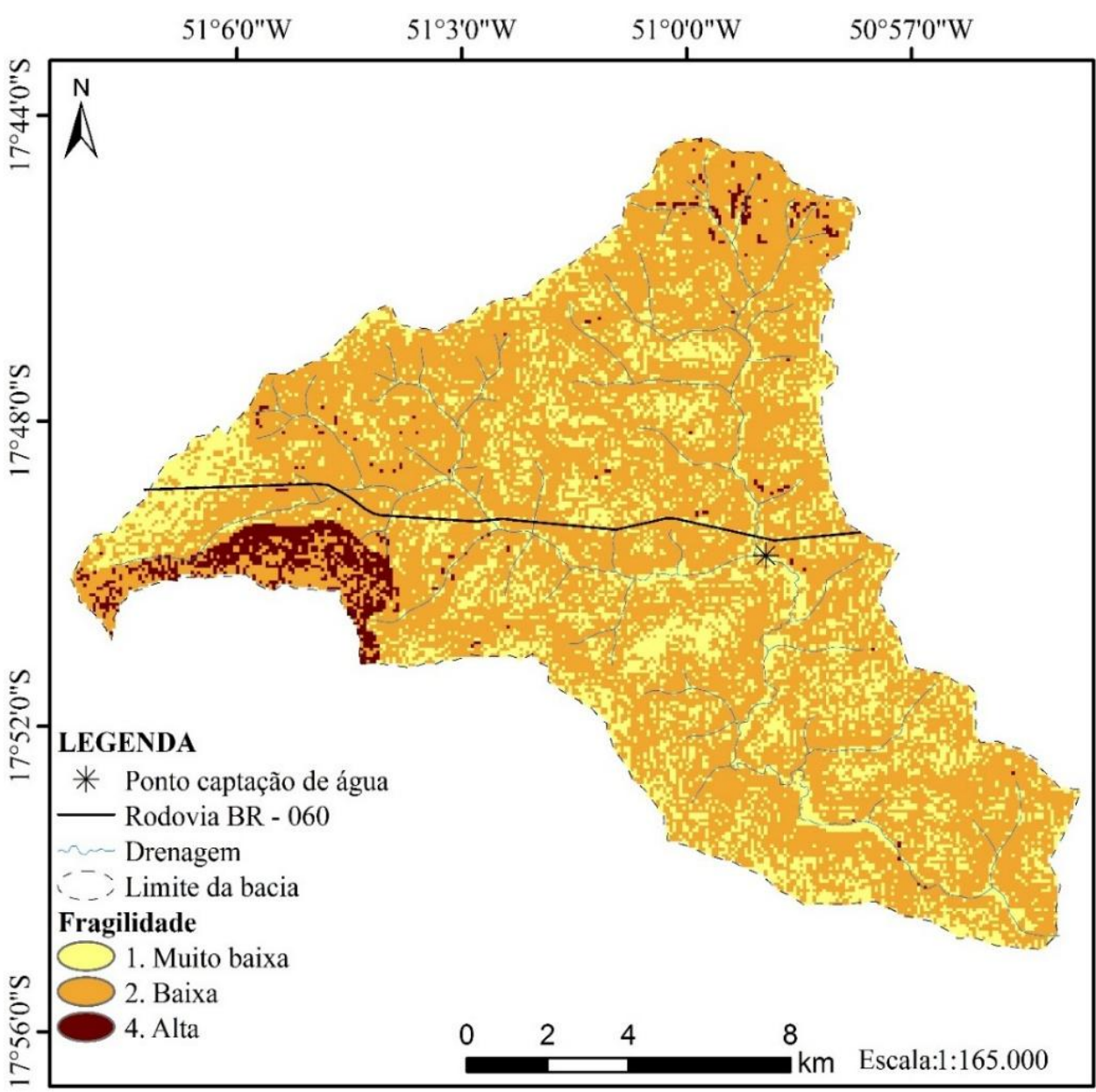

Figura 14. Fragilidade ambiental potencial na bacia do Ribeirão das Abóboras, localizada no município de Rio Verde (GO).

Fonte: Elaborado pelos autores a partir de bases geográficas cedidas pelo USGS (2016) e SIEG (2016).

No centro da Figura 16 observa-se solo exposto/cascalheira, onde o grau de proteção do solo foi classificado como baixo. Por ser a bacia do Ribeirão das Abóboras importante para o fornecimento de água para a população urbana de Rio Verde (GO), para os processos produtivos da BRF e outros usos múltiplos, o recomendável é que essa área seja recuperada. 
Dos Santos Alves, W., Scopel, I. y Perini Martins, A. (2017): “Análise da fragilidade ambiental da bacia do Ribeirão das Abóboras, em Rio Verde, Sudoeste de Goiás”, GeoFocus (Artículos), no 19, p. 81-108. ISSN: 1578-5157 http://dx.doi.org/10.21138/GF.556

No centro da Figuras 17 e Figura 18 observa-se área com presença de erosão onde a fragilidade potencial foi classificada como alta, especificamente na microbacia do Córrego Marimbondo, o principal afluente do Ribeirão das Abóboras.

Estes resultados inferem que a bacia hidrográfica em estudo apresenta condições climáticas favoráveis à sua conservação, desde que o uso da terra e cobertura vegetal não busque somente o desenvolvimento socioeconômico, mas também a sustentabilidade ambiental.

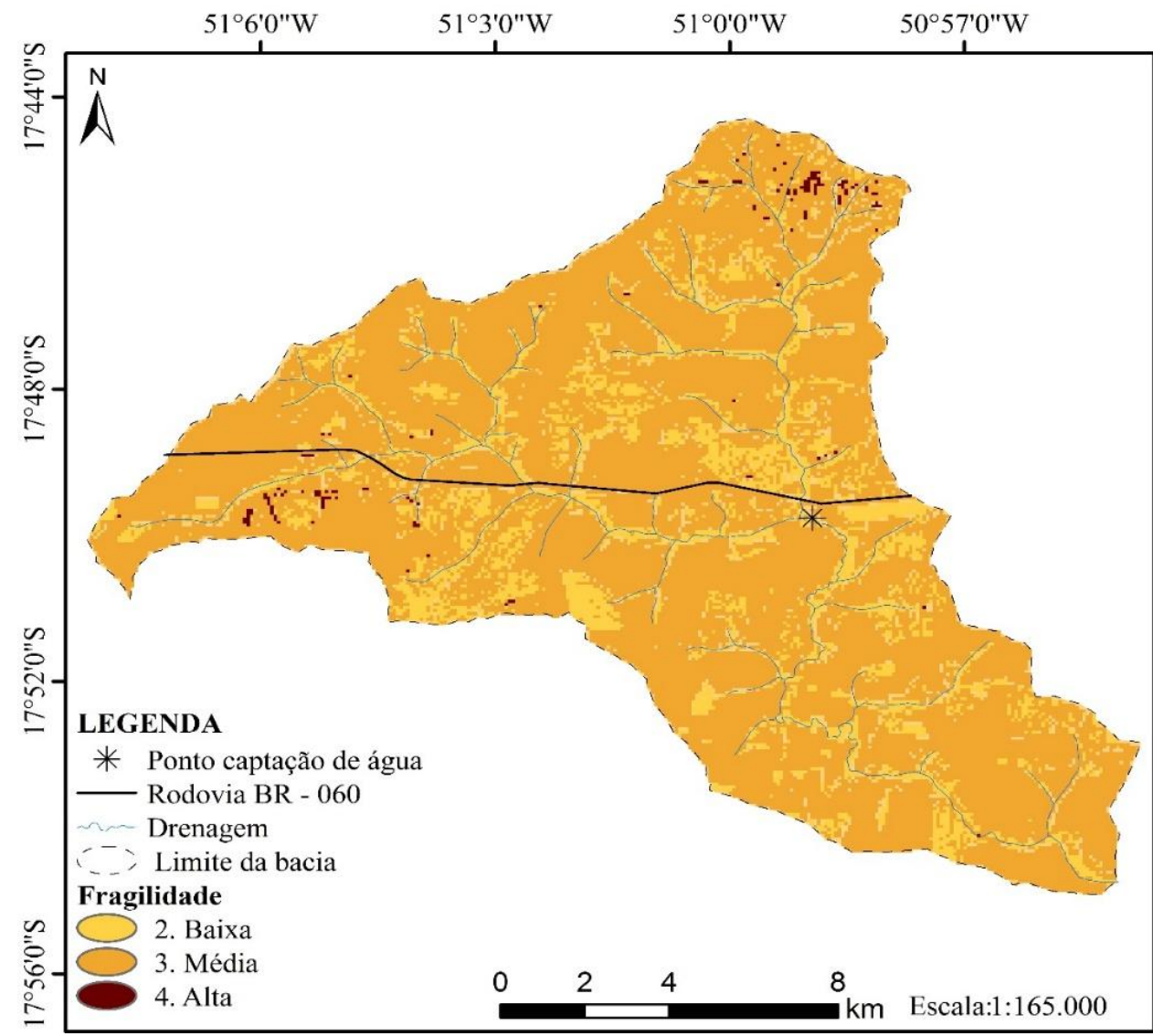

Figura 15. Fragilidade ambiental emergente na bacia do Ribeirão das Abóboras, localizada no município de Rio Verde (GO).

Fonte: Elaborado pelos autores a partir de bases geográficas cedidas pelo USGS (2016) e SIEG (2016). 
Dos Santos Alves, W., Scopel, I. y Perini Martins, A. (2017): “Análise da fragilidade ambiental da bacia do Ribeirão das Abóboras, em Rio Verde, Sudoeste de Goiás", GeoFocus (Artículos), no 19, p. 81-108. ISSN: 1578-5157 http://dx.doi.org/10.21138/GF.556

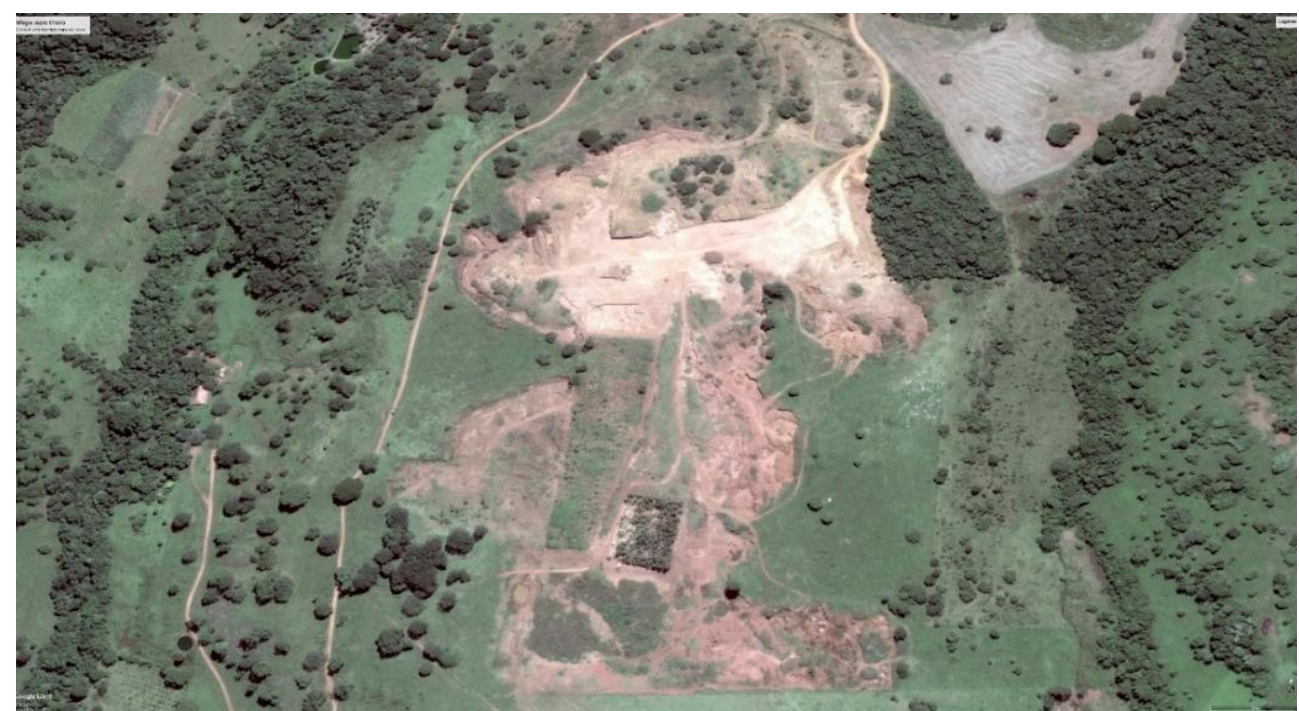

Figura 16. Solo exposto/cascalheira na bacia do Ribeirão das Abóboras, localizada no município de Rio Verde (GO).

Fonte: Google Earth Pro (2016).

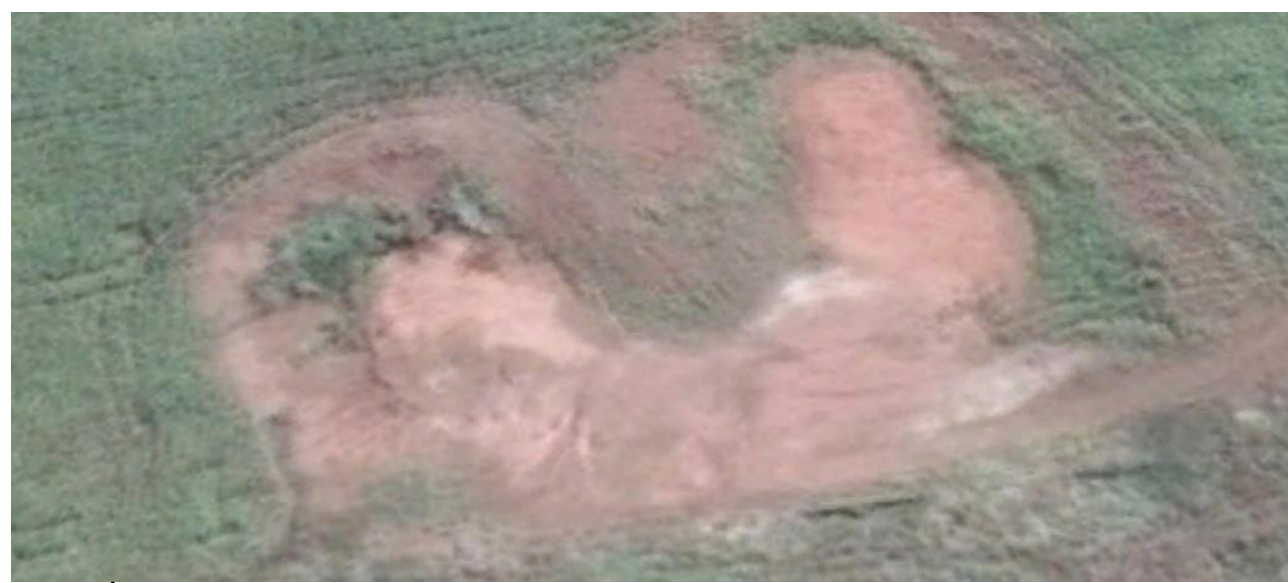

Figura 17. Área com presença de erosão laminar na microbacia do Córrego Marimbondo, afluente da bacia do Ribeirão das Abóboras, localizada no município de Rio Verde (GO). Fonte: Google Earth Pro (2016).

O uso da terra e cobertura vegetal diversificado dentro da área de estudo devem visar à redução do impacto da gota da chuva sobre os solos, uma vez que a área de Argissolos com $4,59 \%$ do total da área de estudo, conforme modelo de Ross (2004), é caracterizada como de média fragilidade; e levando em consideração ainda que, quanto a declividade, as áreas de média, alta e muito alta fragilidade observadas somam $17,94 \%$ da área total da bacia hidrográfica. 
Dos Santos Alves, W., Scopel, I. y Perini Martins, A. (2017): “Análise da fragilidade ambiental da bacia do Ribeirão das Abóboras, em Rio Verde, Sudoeste de Goiás”, GeoFocus (Artículos), no 19, p. 81-108. ISSN: 1578-5157 http://dx.doi.org/10.21138/GF.556

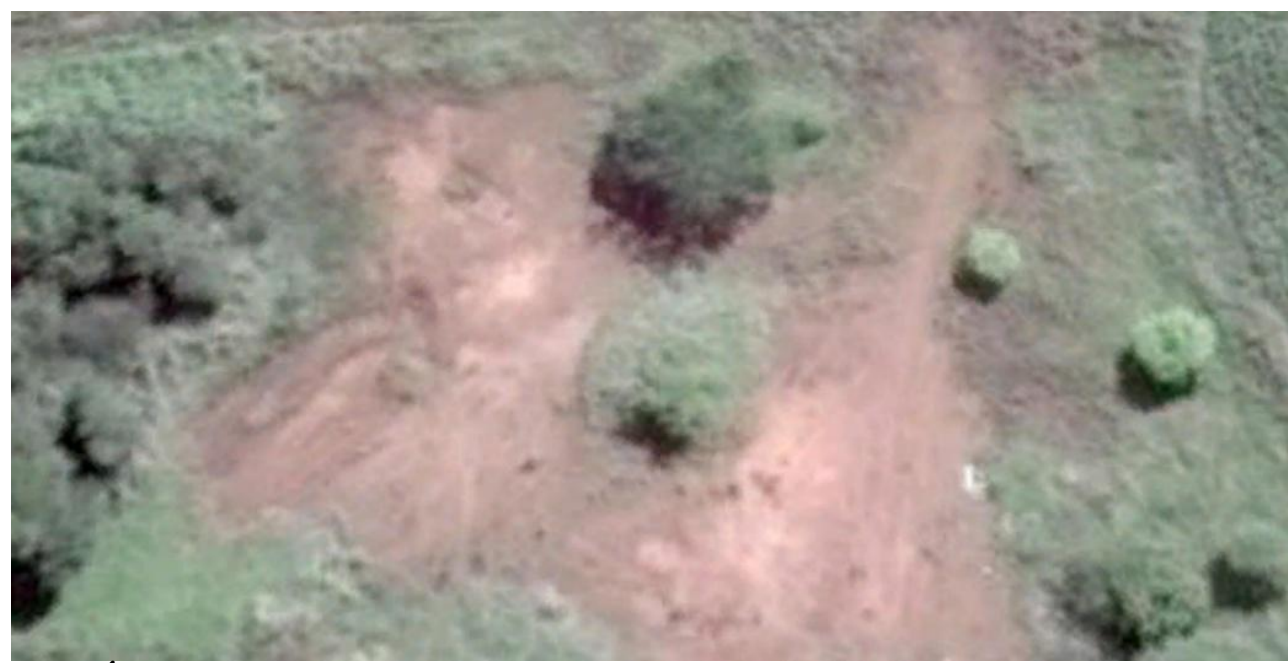

Figura 18. Área com presença de erosão laminar na microbacia do Córrego Marimbondo, afluente da bacia do Ribeirão das Abóboras, localizada no município de Rio Verde (GO). Fonte: Google Earth Pro (2016).

Conforme Cabral et al. (2011), o constante uso do solo para agricultura e formação de pastagens remete em danos ao meio ambiente, pois a ocupação inadequada é um exemplo de impacto ambiental negativo.

\section{Conclusão}

A bacia do Ribeirão das Abóboras foi classificada como de médio grau de erosividade, sendo sua maior parte enquadrada na classe de fragilidade potencial baixa e fragilidade emergente média. Constatou-se ocorrência de declividades com maior grau de influência nos processos erosivos, solos de média fragilidade e área com grau de proteção muito baixa, próximos aos cursos hídricos, mostrando que a área de estudo é propícia ao uso agrícola, desde que se vise o desenvolvimento sustentável, através da aplicação de práticas de uso e manejo conservacionistas do solo, tais como práticas conservacionistas vegetativas, edáficas e mecânicas, e do cumprimento das exigências das leis ambientais vigentes.

As perdas de solos observadas nas áreas de baixa proteção ambiental e alta fragilidade ambiental potencial inferem que ações devem ser implementadas no intuito de minimizar, evitar e recuperar essas áreas com prejuízos ambientais e, consequentemente, econômicos.

Estes resultados irão subsidiar o planejamento e a gestão ambiental das bacias hidrográficas localizadas no município de Rio Verde $(\mathrm{GO})$ e em outras regiões, proporcionando equilíbrio ambiental.

\section{Referências}

Alves, W. S.; ScopeL, I.; Martins, A. P.; Morais, W. A. (2016): “Análise morfométrica da bacia do Ribeirão das Abóboras - Rio Verde (GO)”. Geociências, v. 35, n. 4, p. 652-667.

Bertoni, J. C. e Lombardi Neto, J. (2005): Conservação do solo. 5 ed. São Paulo (SP): Icone. 
Dos Santos Alves, W., Scopel, I. y Perini Martins, A. (2017): “Análise da fragilidade ambiental da bacia do Ribeirão das Abóboras, em Rio Verde, Sudoeste de Goiás”, GeoFocus (Artículos), no 19, p. 81-108. ISSN: 1578-5157 http://dx.doi.org/10.21138/GF.556

BDMEP - Banco de Dados Meteorológicos para Ensino e Pesquisa. (2015): Dados de precipitação de janeiro de 1996 a dezembro de 2015. Disponível em: http://www.inmet.gov.br/projetos/rede/pesquisa/ (Consultado13-03-2016).

Botelho, R. G. M. (1999): "Planejamento ambiental em microbacia hidrográfica" In: GUERRA, A. J. T., SILVA, A. S. da; Botelho, R. G. M. (Organizadores): Erosão e conservação dos solos: conceitos, temas e aplicações. Rio de Janeiro: Bertrand Brasil.

BRASIL. Presidência da República. Lei $\mathrm{n}^{\circ}$ 2.651. Dispõe sobre a proteção da vegetação nativa; altera as Leis $\mathrm{n}^{\text {os }}$ 6.938, de 31 de agosto de 1981, 9.393, de 19 de dezembro de 1996, e 11.428, de 22 de dezembro de 2006; revoga as Leis $\mathrm{n}^{\text {os }} 4.771$, de 15 de setembro de 1965, e 7.754, de 14 de abril de 1989, e a Medida Provisória $n^{0}$ 2.166-67, de 24 de agosto de 2001; e dá outras providências. Diário Oficial [da] República Federativa do Brasil. Brasília, DF, 25 de maio de 2012. Disponível em:

$<$ http://pesquisa.in.gov.br/imprensa/jsp/visualiza/index.jsp?jornal=1\&pagina=1\&data=28/05/2012>.

(Consultado 29-06-2016).

Cabral, J. B. P., Rocha, I. R., Martins, A. P., Assunção, H. F., Begat, V. A. (2011): "Mapeamento da fragilidade ambiental da bacia hidrográfica do rio Doce (GO)", utilizando técnicas de Geoprocessamento, Revista Geofocus, n. 11, p. 51-69.

Carvalho, N. O. Hidrossedimentologia Prática. (1994): CPRM - Companhia de Pesquisa em Recursos Minerais (RJ): Brasil.

Congalton, R. G., Green, K. (2009): Assessing the accuracy of remotely sensed data: principles and practices. 2 ed. New York: Lewis Publishers.

Crepani, E., Medeiros, J. S., Hernandez Filho, P., Florenzano, T. G., Duarte, V. e Barbosa, C. C. F. (2001): Sensoriamento remoto e geoprocessamento aplicados ao zoneamento ecológicoeconômico e ao ordenamento territorial, INPE, 64p. Disponível em: http://www.dsr.inpe.br/laf/sap/artigos/CrepaneEtAl.pdf. (Consultado 09-01-2017).

Donha, A. G., Souza, L. C. D. P. e Sugamosto, M. L. (2006): "Determinação da fragilidade ambiental utilizando técnicas de suporte à decisão e SIG", Revista Brasileira de Engenharia Agrícola e Ambiental, v. 10, n. 1, p. 175-181.

Embrapa. Agência Embrapa de Informação Tecnológica. (2017): Solos Tropicais/Argissolos. Disponível em:

http://www.agencia.cnptia.embrapa.br/gestor/solos_tropicais/arvore/CONTAG01_7_221220061 1538.html (Consultado 08-01-2017).

Embrapa - Empresa Brasileira de Pesquisa Agropecuária (2013): Sistema Brasileiro de Classificação de Solos. 3 ed. Editores Técnicos, Humberto Gonçalves dos Santos et al. Rio de Janeiro - RJ: Embrapa Solos.

Ferreira, W. S. (2010): Cultivo do milho e da soja em sucessão as culturas de safrinha em Rio Verde - GO. Dissertação (Mestrado em Produção Vegetal) - Universidade de Rio Verde, Rio Verde (GO).

Gonçalves, G. G. G., Daniel, O., Comunello, E., Vitorino, A. C. T. e Arai, F. C. (2011): "Determinação da fragilidade ambiental de bacias hidrográficas", Revista Floresta, v. 41, n. 4, p. 797-808.

IBGE - Instituto Brasileiro de Geografia e Estatística. (2017): Cidades. Disponível em: http://www.cidades.ibge.gov.br/xtras/perfil.php?lang=\&codmun=521880\&search=goias|rio-verde. (Consultado 09-01-2017). 
Dos Santos Alves, W., Scopel, I. y Perini Martins, A. (2017): “Análise da fragilidade ambiental da bacia do Ribeirão das Abóboras, em Rio Verde, Sudoeste de Goiás”, GeoFocus (Artículos), no 19, p. 81-108. ISSN: 1578-5157 http://dx.doi.org/10.21138/GF.556

Kawakubo, F. S., Morato, R. G., Campos, K. C., Luchiari, A. E., Ross, J. L. S. (2005): "Caracterização empírica da fragilidade ambiental utilizando geoprocessamento", In: XII Simpósio Brasileiro de Sensoriamento Remoto, p. 2203-2210. Disponível em: file:///C:/Users/Dablio/Downloads/ROSS+-

+Caracteriza \%C3 \%A7 \%C3 \%A3oEmpiricaDaFragilidadeAmbiental \%20(1).pdf (Consultado 09-012017).

Landis, R., Koch, G. G. (1977): "The measurement of observer agreement for categorical data”, Revista Biometrics, v.33, n.1, p.159-174.

Latrubesse, E. M. e Carvalho, T. M. (2006): Geomorfologia do Estado de Goiás e Distrito Federal. Secretaria de Industria e comércio. Superintendência de Geologia e mineração. Goiânia. Disponível em: http://www.sieg.go.gov.br/ (Consultado 02 -01-2016).

Martins, T. I. S. e Rodrigues, S. C. (2012): "Análise e mapeamento dos graus de fragilidade ambiental da bacia do médio - baixo curso do rio Araguari, Minas Gerais", Revista Caderno de Geografia, v. 22, n. 38.

Prado, R. B. Ferreira, C. E. G. Benites, V. M. Naumov, A. (2009): "Mapeamento e descrição do padrão de uso e cobertura da terra em municípios do sudoeste goiano a partir de imagens orbitais TM/Landsat-5", Embrapa Solos, Boletim de pesquisa 148, 54p.

Ramalho Filho, A., Beek, K. L. (1995): Sistema de avaliação da aptidão agrícola das terras. Rio de Janeiro, $3^{\mathrm{a}}$ ed., Embrapa - CNPS. Disponível em: http://library.wur.nl/isric/fulltext/isricu_i11658_001.pdf (Consultado 09-01-2017).

Ross, J. L. S. (1994): “Análise empírica da fragilidade dos ambientes naturais e antropizados”, Revista do Departamento de Geografia, São Paulo - SP n.8. FFLCH-USP, 1994 p.63-74.

Rosenfield, G. H., Fitzpatrick-Lins, K. (1986): "A coefficient of agreement as a measure of thematic classification accuracy", Photogrammetric Engineering and Remote Sensing, 52, n.2, p.223-227.

Simões, L. B. (2001): Integração entre um modelo de simulação hidrológica e sistema de informação geográfica na delimitação de zonas tampão ripárias. Tese (Doutorado em Agronomia/Energia na Agricultura) - Faculdade de Ciências Agronômicas, Universidade Estadual Paulista, Botucatu.

USGS - United States Geological Survey. (2016): EarthExplorer. Disponível em: https://earthexplorer.usgs.gov/ (Consultado 20-01-2016).

SIEG - Sistema Estadual de Geoinformação de Goiás. (2016): Base

Cartográfica para Download. http://www.sieg.go.gov.br/ (Consultado 02 -01-2016).

SpörL, C., Ross, J. L. S. (2004): “Análise comparativa da fragilidade ambiental com aplicação de três modelos", Revista GEOUSP - Espaço e Tempo, n. 15, p. 39-49.

Wischmeier, W. H. e Smith, D. D. (1978): Predicting rainfall erosion losses: a guide to conservation planning. Washington, United States Department of Agriculture, 58p. (Agriculture Handbook, 537). 